\title{
¿Impact of Lateral Groundwater Flow and Subsurface Lower Boundary Conditions on Atmospheric Boundary Layer Development over Complex Terrain
}

\author{
MARY M. ForRester AND REED M. MAXWELL \\ Hydrologic Science and Engineering Program, Geology and Geological Engineering Department, \\ Colorado School of Mines, Golden, Colorado
}

(Manuscript received 25 February 2019, in final form 1 February 2020)

\begin{abstract}
Credible soil moisture redistribution schemes are essential to meteorological models, as lower boundary moisture influences the balance of surface turbulent fluxes and atmospheric boundary layer (ABL) development. While land surface models (LSMs) have vastly improved in their hydrologic representation, several commonly held assumptions, such as free-draining lower boundary, one-dimensional moisture flux, and lack of groundwater representation, can bias the terrestrial water balance. This study explores the impact of LSM hydrology representation on ABL development in the Weather Research and Forecasting (WRF) meteorological model. The results of summertime WRF simulations with Noah LSM, characterized by 2-m-thick soil and one-dimensional flow, are shown for a domain in the Colorado Rocky Mountain headwaters region. A reference WRF simulation is compared to 1 ) the same model with soil moisture initialized by the hydrologic model ParFlow; 2) a deep, free-draining simulation; and 3) WRF coupled to ParFlow, a three-dimensional, integrated groundwater-surface water model. Results show that both lateral transport of groundwater and the rate of drainage from the lower soil layer can weaken or reverse the coupling strength between evaporative fraction and $\mathrm{ABL}$ over a 5-month summer period. The resulting shifts in low-level moist convection in river valleys and thermally driven airflows yield strengthened anabatic upslope winds and perturbations to regional precipitation.
\end{abstract}

\section{Introduction}

Groundwater, soil, vegetation, and the atmosphere are intimately coupled through complex and highly nonlinear interactions (Brubaker and Entekhabi 1996; Entekhabi et al. 1996; Rodriguez-Iturbe 2000). For decades, meteorological models, with land surface models (LSMs) as their lower boundary, have advanced in their ability to not only provide dependable predictions of atmospheric states and surface recharge, but also to diagnose this complicated exchange of moisture and energy fluxes at the land-atmosphere interface. LSMs in particular have improved considerably in their representation of hydrologic and ecological processes (Henderson-Sellers et al. 1993; Best et al. 2015), having evolved from first-generation, shallow-depth models

Denotes content that is immediately available upon publication as open access.

Corresponding author: Mary Michael Forrester, mforrest@ mines.edu with bucket hydrology and minimal soil heat conduction (e.g., Manabe 1969), to multilayer models capturing vegetation conductance, carbon balance modeling, Richardsbased infiltration schemes, snowpack and frozen ground simulation, and saturation or infiltration excess runoff generation (e.g., Chen and Dudhia 2001; Dickinson et al. 1998; Lawrence et al. 2011; Sellers et al. 1986). Yet, despite advancements in model complexity, hydrologic representation in LSMs operates under several assumptions, discussed below, that may prejudice simulations of soil moisture and soil-atmosphere exchange. Given the wellestablished influence of soil moisture heterogeneity and magnitude on the atmosphere (Kim and Wang 2007; Kollet and Maxwell 2008; Koster et al. 2003; Santanello et al. 2011; Seuffert et al. 2002), appropriate LSM moisture characterization is an important problem. A growing number of studies address this issue by improving realism of LSM terrestrial hydrology and capturing the connection of the groundwater and energy cycles (Anyah et al. 2008; Gulden et al. 2007; Maxwell and Kollet 2008a; Miguez-Macho et al. 2007; Niu et al. 2007; Rahman et al. 2015; Keune et al. 2016; Maxwell and Condon 2016). 
The limited dimensionality of LSMs traditionally prohibits lateral water flow in the subsurface. Most LSMs, including those used in meteorological and climate models, route moisture in one vertical dimension and allow no lateral communication between vertical soil columns. Such an assumption can lead to overestimates of soil moisture, and subsequently latent heat flux, in topographic highs relative to valleys, given that the model omits routing influenced by geomorphology (Soulis et al. 2000). This could be particularly problematic in regions of complex terrain and heavily orographic precipitation. The absence of aquifer representation and generally shallow soil depth (2-10 m) in LSMs means that well-known controls of groundwater on soil moisture and surface energy (Keune et al. 2016; Maxwell and Condon 2016; Rahman et al. 2015) may be overlooked. Groundwater's longterm memory to atmospheric anomalies and known groundwater-atmosphere feedbacks (Entekhabi et al. 1996) motivate the use of improved subsurface storage schemes. Choice of soil hydraulic parameterizations are also important in mesoscale meteorological models; Braun and Schädler (2005) compared several models, finding that the soil hydraulic parameterizations based on van Genuchten (1980) performed better than ClappHornberger (Clapp and Hornberger 1978; Cosby et al. 1984) models. Free-draining boundary conditions, in which water may freely drain at the rate of conductivity of the lowest node or based on slope-informed parameters, are often applied at the bottom of LSM soils and could bias simulated soil moisture content and prohibit surface water balance closure (Yeh and Eltahir 2005), which can further corrupt estimates of surface turbulent fluxes.

In the past decade, a number of fully coupled platforms have been developed which resolve feedbacks from bedrock to atmosphere and provide a more holistic view of the coupled water and energy cycles than some meteorological models used for operational forecasts. Recently, Shrestha et al. (2014) coupled the ParFlow integrated hydrologic model (Jones and Woodward 2001) with the Consortium for Small-Scale Modeling (COSMO; Baldauf et al. 2011), using the Community Land Model (CLM; Oleson et al. 2008). The coupled platform, also known as the Terrestrial Systems Modeling Platform (TerrSysMP), has shown improved estimates of surface fluxes with incorporation of integrated terrestrial hydrology in idealized and real data simulations (Shrestha et al. 2014); TerrSysMP was also applied over the European Coordinate Regional Downscaling Experiment (CORDEX) domain, with results suggesting strong surface energy and lower atmosphere dependence upon subsurface hydrofacies distribution and groundwater configuration (Keune et al. 2016). In more recent work,
TerrSysMP simulations over western Germany showed that augmented subsurface and land surface physics do not result in consistent improvements in land surface and atmospheric states (Sulis et al. 2018), although synoptic forcings were a large uncertainty factor. Earlier coupled system experiments were performed with the coupled ARPS-ParFlow (the Advanced Regional Prediction System), and later with WRF-ParFlow (the Weather Research and Forecasting mesoscale meteorological model) (Skamarock et al. 2008; Xue et al. 2000). Maxwell et al. (2007) showed atmospheric boundary layer development was highly sensitive to soil moisture redistribution with ARPS-ParFlow, while Maxwell et al. (2011) demonstrated the application of fully coupled, semi-idealized simulations to both wind-energy and rainfall-runoff forecasts in WRF-ParFlow. Anyah et al. (2008) found improved evapotranspiration and even precipitation estimates in arid regions following the incorporation of water table dynamics and subsequently wetter soils, using the Regional Atmospheric Modeling System (RAMSHydro; Anyah et al. 2008; Miguez-Macho et al. 2007). The WRF-Hydro model was originally developed as a tool for coupling terrestrial hydrology modeling platforms and LSMs to WRF (Gochis et al. 2015), and the stand-alone coupled modeling system has been applied to meteorological domains around the world (e.g., Senatore et al. 2015; Yucel et al. 2015). For example, Senatore et al. (2015) found that the fully coupled WRF-Hydro model modestly outperformed WRF-only simulations with respect to observed precipitation. They also showed higher soil moisture content, and consequently higher latent heat flux, in the fully coupled platform, which may be attributed to 1) the hydrologic model's ability to redistribute moisture to neighboring soil columns and 2) the ability for excess water to reinfiltrate, rather than be altogether removed from the water cycle in the uncoupled simulations. A WRF configuration over the central United States was also found to yield improved simulated coupling between soil moisture and lifting condensation level (LCL) when a groundwater component, as well as vegetative growth, were incorporated (Jiang et al. 2009).

While the sensitivity of meteorological model performance to terrestrial hydrology representation is an ongoing question, the coupled system platforms described above add to our understanding of groundwateratmosphere coupling and allow for the diagnosis of coupling behavior previously unavailable. In this study, we explore the interaction of lower boundary terrestrial hydrology representation and topographic complexity on modeled meteorological states using the ParFlowWRF hydrologic-atmospheric model (Maxwell et al. 2011). This modeling platform has previously been used 
to analyze mechanistic relationships between groundwater table depth and moisture and energy in the lower atmosphere (Maxwell et al. 2011), as well as to highlight the potential for subsurface hydraulic conductivity realizations to generate ensembles via land energy perturbations (Williams and Maxwell 2011). Here, we compare a long-range, uncoupled WRF-only forecast to fully coupled ParFlow-WRF configurations, in order to test the influence of subsurface soil moisture redistribution parameterizations and dynamic water table depth on predicted meteorological states. The model domain of choice, encompassing several headwater watersheds in the Colorado Rocky Mountain headwaters, is one characterized by highly complex terrain, which will induce lateral routing of moisture to topographic convergent zones in the fully coupled model. Below, we describe the experiment in greater detail, focusing on the major conceptual differences between lower boundary configurations in section 2a. Section $2 b$ highlights the governing equations for soil moisture and infiltration that differ between the WRF-only and fully coupled ParFlow-WRF simulations. A description of the model domain, input parameters, and initial and boundary condition development is given in section $2 \mathrm{c}$, and model validation datasets are described in section $2 \mathrm{~d}$.

The primary goal of this study is to examine the response of atmospheric boundary layer development and land-atmosphere coupling over complex terrain to assumptions prevalent in LSMs discussed above, namely, one-dimensional (vertical-only) soil water redistribution; shallow LSM depth and lack of groundwater component; choice of soil hydraulic parameters; and choice of initial soil moisture condition. Incorporating lateral groundwater movement and a dynamic water table will move soil moisture away from ridges and into valleys, contrasting the precipitation-dependent soil water content in the WRF-only model that can leave topographic lows inappropriately dry. In this way, ridges (valleys) will experience lower (higher) evaporative fraction with the addition of dynamic groundwater components, and land-atmosphere coupling will be affected. We hypothesize that these affects, specifically applied in a region of complex terrain, will result in changes to thermally driven orographic convection, flows, and precipitation. Models are validated against observed AmeriFlux surface energy and meteorological variables and compared to available radiosonde measurements (section 3a). After discussing the impact of lower boundary condition on surface energy variables, convective boundary layer development, and land-atmosphere coupling (sections $3 \mathrm{~b}$ and $3 \mathrm{c}$ ), we address two important drivers of regional meteorology, including moist convection in valleys and thermally driven anabatic flows (section 3d) and their sensitivity to terrestrial hydrology.

\section{Methods}

\section{a. Conceptual experiment design}

This study examines the influence of the lower boundary condition on simulated atmospheric states, by comparing meteorological model configurations that vary in their initial soil moisture condition or in their physical hydrology representation. Figure 1 shows a conceptual diagram of the controlled experiment. The three models illustrated here share identical meteorological models, LSMs, initial atmospheric conditions and lateral atmospheric boundary conditions, and static LSM variables; they differ only in the way soil moisture was dynamically redistributed throughout the subsurface.

The default atmospheric model, WRF, employs the Noah LSM with four soil layers as its lower boundary condition (Fig. 1a); this model will act as our control. Noah governs the development of heterogeneous soil moisture states, and like many LSMs it assumes onedimensional moisture flux, shallow (2-m total) soil depth without deeper storage or groundwater, and no surface hydrology component. Water in the subsurface gravitationally drains from the lowest soil moisture layer at a rate scaled by a factor representing the slope of the cell, with larger surface slopes representing larger drainage. Drained moisture from the subsurface is not stored and may not feedback to soil water through capillarity at later times. Initial soil moisture conditions in the baseline WRF Model were supplied by the WRF Preprocessing System (WPS), which downscales coarserresolution meteorological products, in this case from the $1^{\circ}$ gridded NCEP FNL (Final) Operational Global Analysis data, for WRF's initial and boundary conditions.

Our perturbed model simulations include 1) WRF coupled to a hydrologic model $\left.\left(\mathrm{PFWRF}_{3 \mathrm{D}}\right), 2\right) \mathrm{WRF}$ initialized by a hydrologic model ( $\left.\mathrm{WRF}_{\mathrm{PFIC}}\right)$, and 3$)$ a simulation with deep, free-draining subsurface moisture $\left(\mathrm{PFWRF}_{\mathrm{FD}}\right)$ (Table 1). These configurations respectively test three-dimensional groundwater flow, model initial condition, and lower boundary drainage rate, relative to the control.

The fully coupled configuration, $\mathrm{PFWRF}_{3 \mathrm{D}}$, similarly employs the Weather Research and Forecasting Model with Noah LSM, but while the LSM still handles evapotranspiration and the surface energy budget, its soil moisture calculation is replaced with ParFlow, an integrated surface-subsurface hydrology model (Fig. 1c). The model is also deeper, with the same four Noah soil layers and a 100-m-deep geology layer, for a total model depth of $102 \mathrm{~m}$, in order to 
A. WRF: Landatmosphere modeling

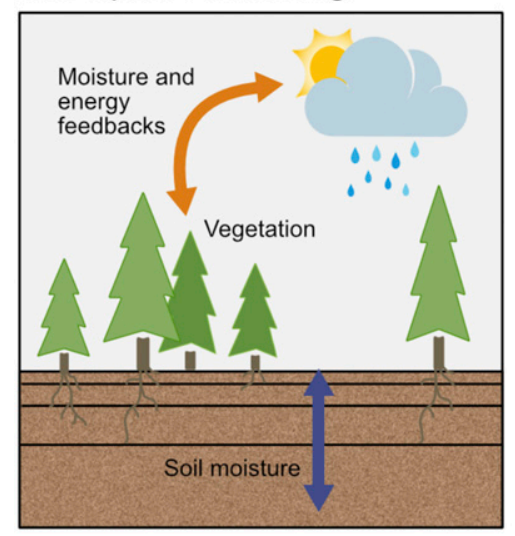

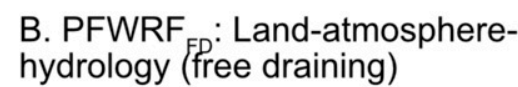
hydrology (free draining)

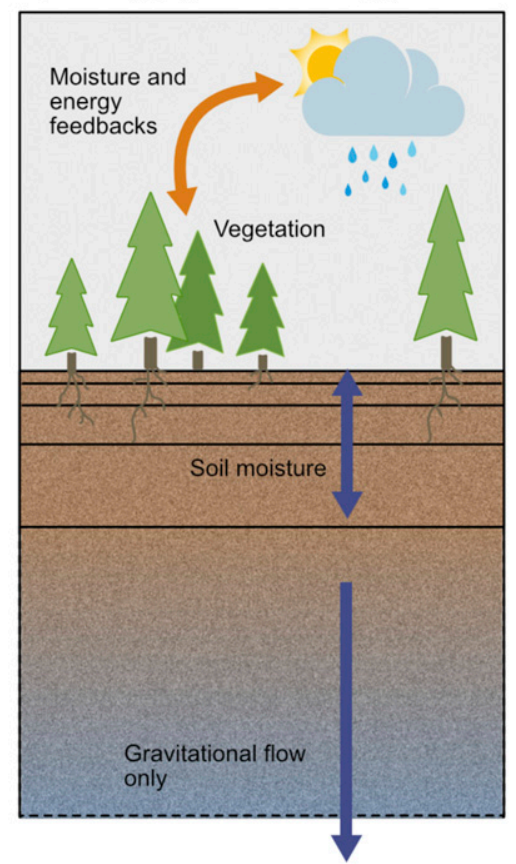

C. PFWRF : Land-atmospherehydrology (3D)

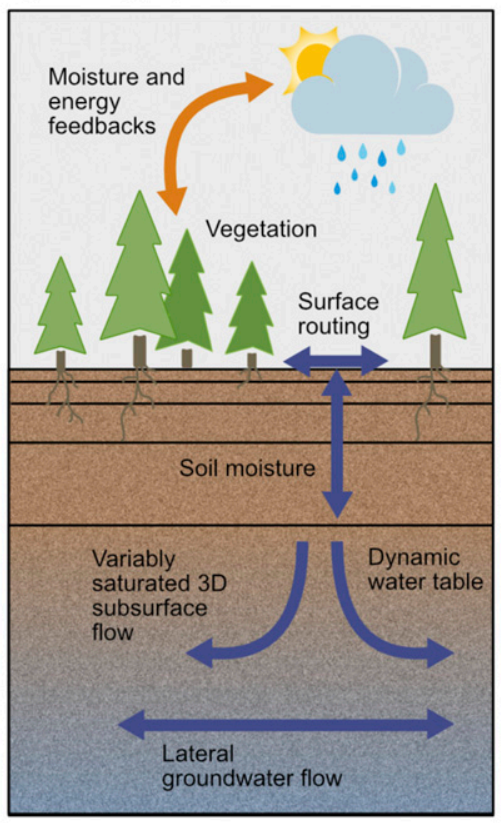

FIG. 1. Conceptual model of hydrologic schemes in WRF. (a) Default WRF-only uncoupled model with column-based moisture redistribution is the scheme for WRF and $\mathrm{WRF}_{\mathrm{PFIC}}$. (b) PFWRF $\mathrm{FD}_{\mathrm{F}}$ extends the model depth an additional $100 \mathrm{~m}$ with an added layer but maintains one-dimensional (vertical) flux and free-draining lower boundary. (c) $\mathrm{PFWRF}_{3 \mathrm{D}}$ routes moisture in three dimensions, resolves surface water routing and reinfiltration, and maintains a no-flow lower boundary condition.

capture groundwater-vadose zone exchange. $\mathrm{PFWRF}_{3 \mathrm{D}}$ therefore differs from WRF in that its simulated, variably saturated moisture flux is three-dimensional, such that lateral movement of groundwater and a dynamic water table are resolved. The initial condition for PFWRF $_{3 \mathrm{D}}$ is ParFlow's spun-up hydrologic state for the region (described in further detail in section $2 \mathrm{c}$ ).

The free-draining model, PFWRF $_{\mathrm{FD}}$, was designed to mimic WRF's vertical-only subsurface moisture flux while extending the lower boundary condition deeper into the subsurface and test the influence of drainage rate on atmospheric states. In this case, ParFlow rather than Noah again routes water vertically in the subsurface to a depth of $102 \mathrm{~m}$, but lateral water flow is eliminated and a free draining lower boundary condition

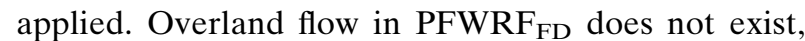
and water primarily moves downward (never laterally) through the subsurface, exiting the model domain through the lower boundary at the rate of hydraulic permeability in the lowest model layer. The rate of drainage for the $\mathrm{PFWRF}_{\mathrm{FD}}$ model is therefore faster than the baseline WRF Model. To keep the free draining model as close to the control as possible, the initial moisture condition was a surface-level initial

TABLE 1. Configurations of the WRF Model tested over the Colorado Rocky Mountain headwaters domain. Note that PFWRF $F_{3 D}$ and $\mathrm{PFWRF}_{\mathrm{FD}}$ contain an additional model layer representing geology and groundwater below the four soil layers.

\begin{tabular}{|c|c|c|c|c|c|c|c|}
\hline Model name & $\begin{array}{l}\text { Assumption } \\
\text { tested }\end{array}$ & $\begin{array}{l}\text { Lower boundary } \\
\text { drainage }\end{array}$ & $\begin{array}{l}\text { Dimensionality } \\
\text { (subsurface) }\end{array}$ & Initial condition & $\begin{array}{c}\text { Model } \\
\text { depth }(m)\end{array}$ & $\begin{array}{c}\text { Soil } \\
\text { depth }(\mathrm{m})\end{array}$ & $\begin{array}{l}N \text { soil } \\
\text { layers }\end{array}$ \\
\hline WRF & N/A: Control, baseline & $\begin{array}{l}\text { Noah LSM: Parameterized } \\
\text { relative to slope category }\end{array}$ & 1D moisture flux & WPS & 2 & 2 & 4 \\
\hline $\mathrm{PFWRF}_{3 \mathrm{D}}$ & $\begin{array}{l}\text { Lateral flow and } \\
\text { groundwater }\end{array}$ & No-flow boundary & 3D moisture flux & ParFlow & 102 & 2 & 4 \\
\hline $\mathrm{PFWRF}_{\mathrm{FD}}$ & Free drainage & $\begin{array}{l}\text { Free draining (conductivity } \\
\text { of lowest geology layer) }\end{array}$ & 1D moisture flux & $\begin{array}{l}\text { Saturated soils, } \\
\text { similar to WPS }\end{array}$ & 102 & 2 & 4 \\
\hline $\mathrm{WRF}_{\mathrm{PFIC}}$ & Initial condition & $\begin{array}{l}\text { Noah LSM: Parameterized } \\
\text { relative to slope category }\end{array}$ & 1D moisture flux & ParFlow & 2 & 2 & 4 \\
\hline
\end{tabular}


water table, because initial soil moisture conditions supplied by WPS were at or near saturation for the majority of the domain.

Model configurations described in Fig. 1 vary in their physical governing mechanisms for terrestrial hydrology calculations. We also tested the influence of initial soil moisture condition by comparing WRF with $\mathrm{WRF}_{\mathrm{PFIC}}$. While its model physics are identical to WRF's (Fig. 1a), the $\mathrm{WRF}_{\mathrm{PFIC}}$ simulation uses an initial soil moisture condition supplied by the ParFlow hydrologic model spinup process (described in section $2 \mathrm{c}$ ). $\mathrm{WRF}_{\mathrm{PFIC}}$ and PFWRF therefore share identical initial moisture fields in the subsurface.

\section{b. Model characteristics and governing equations}

As described above, in this study we examine the influence of initial conditions and dynamics of the lower boundary condition in WRF, the Weather Research and Forecasting mesoscale atmospheric model (Skamarock et al. 2008). WRF solves the nonhydrostatic and fully compressible Navier-Stokes equations to calculate threedimensional thermal and kinetic energy and moisture flux in the atmosphere. In all models, the Thompson et al. (2008) bulk microphysics scheme was used for simulated formation of cloud droplets and precipitation fallout. Longwave and shortwave radiation were represented by the Rapid Radiative Transfer Model (Mlawer et al. 1997) and the Dudhia scheme (Dudhia 1989), respectively. Finally, the Yonsei University (YSU) scheme was used for planetary boundary layer dynamics (Hong et al. 2006).

Land surface energy and moisture flux is calculated by the Noah LSM (Chen and Dudhia 2001), which calculates evapotranspiration (ET) as the sum of transpiration from vegetation and direct evaporation from canopy and ground surfaces. The model consists of four soil layers of variable thickness, with the top layer being $0.1 \mathrm{~m}$ thick and consecutively deeper layers are $0.3,0.6$, and $1.0 \mathrm{~m}$, for a total model depth of $2 \mathrm{~m}$. The boundary condition at the bottom is a gravitational flow that is scaled by a parameter representing the slope category for that cell; drained water does not accumulate or feedback to the 2-m soil column through capillary forces. Noah employs a Penman-based approach for calculating potential evaporation (Penman 1948), and a simple linear model by Betts et al. (1997) to calculate direct evaporation. A canopy resistance factor is included to adjust potential evaporation and resolve vegetation transpiration based on Jacquemin and Noilhan (1990). The canopy resistance term, and therefore Noah's estimate of the soil moisture flux at the surface, is a function of vapor pressure deficit and temperature in the lower atmosphere, solar radiation, and soil water content.
The formulation of subsurface moisture content formulation is the key difference between models compared in this study (Fig. 1). WRF and WRF PFIC $_{\text {both estimate }}$ subsurface moisture redistribution using the Noah LSM prognostic equations for soil moisture content. Here, Noah LSM solves Richards' equation [Eq. (1)] (Richards 1931), assuming isotropic, homogeneous, and one-dimensional vertical flow (Chen and Dudhia 2001; Hanks and Ashcroft 1980). The Richards equation may be expressed as a function of volumetric soil water content $\theta$, as shown in Eq. (1) (Chen and Dudhia 2001; Gilding 1991), or in terms of water head potential $h$ (Celia et al. 1990; Hanks and Ashcroft 1980). In Noah, the $\theta$-based form of Richards' equation is expressed as

$$
\frac{\partial \theta}{\partial t}=\frac{\partial}{\partial z}\left[D(\theta) \frac{\partial \theta}{\partial z}\right]+\frac{\partial K(\theta)}{\partial z}+Q,
$$

for vertical coordinate (soil depth) $z$, diffusivity $D$, hydraulic conductivity $K$, and volumetric soil water content $\theta$, at time $t$. The term $Q$ represents sources and sinks for soil water, including runoff, precipitation, and evaporation; WRF-Noah employs the Simple Water Balance (SWB) model to calculate runoff (Schaake et al. 1996). It is important to note that $K$ and $D$ are highly nonlinear functions of the soil water content $\theta$. Diffusivity is given by $D=K(\theta)(\partial \psi / \partial \theta)$ for the soil water tension function $\psi$, and hydraulic conductivity and soil retention are calculated based on the Cosby et al. (1984) equations. These are shown in Eqs. (2) and (3):

$$
\begin{gathered}
K(\theta)=K_{s}\left(\frac{\theta}{\theta_{s}}\right)^{2 b+3}, \\
\psi(\theta)=\psi_{s}\left(\frac{\theta}{\theta_{s}}\right)^{-b},
\end{gathered}
$$

where $K_{s}$ is the saturated soil moisture content, $\theta_{s}$ is the saturated soil matric potential, and $\psi_{s}$ is the saturated soil matric potential, which vary for soil class. The empirical parameter $b$ relates to the soil pore size distribution and is used for curve fitting.

PFWRF $_{3 D}$ and PFWRF $_{F D}$ replace Eqs. (1)-(3) with soil, groundwater, and hydraulic properties represented by ParFlow (Maxwell et al. 2011; Williams and Maxwell 2011). Rather than the $\theta$-based or $h$-based forms, ParFlow solves the three-dimensional mixed form of Richards' equation in terms of hydraulic head (Celia et al. 1990), shown in Eq. (4), and calculates relative saturation and permeability using the van Genuchten (1980) relationships [Eqs. (6) and (7)] (Kollet and Maxwell 2006; Maxwell et al. 2016). 


$$
S_{s} S_{w} \frac{\partial h}{\partial t}+\phi \frac{\partial S_{w}(h)}{\partial t}=\nabla \cdot \mathbf{q}+q_{r},
$$

where $S_{s}$ is the specific storage, $S_{w}$ is the relative saturation, $h$ is the pressure head, and $\phi$ is the porosity. The specific volumetric Darcy flux $\mathbf{q}$ is given by

$$
\mathbf{q}=-\mathbf{K}_{s} k_{r}(h) \cdot \nabla(h-z) .
$$

Here, $\mathbf{K}_{s}$ is the saturated hydraulic permeability tensor and $k_{r}$ is relative permeability. The terrainfollowing grid formulation was used to include a topographic slope component (Maxwell et al. 2016). The van Genuchten (1980) equations used for hydraulic relationships are given in terms of hydraulic head $h$ as

$$
\begin{aligned}
& S_{w}(h)=\frac{s_{\text {sat }}-s_{\text {res }}}{\left[1+(\alpha h)^{n}\right]^{\left(1-\frac{1}{n}\right)}}+s_{\text {res }}, \\
& k_{r}(h)=\frac{\left\{1-\frac{(\alpha h)^{n-1}}{\left[1+(\alpha h)^{n}\right]^{\left(1-\frac{1}{n}\right)}}\right\}}{\left[1+(\alpha h)^{\beta}\right]^{\left(1-\frac{1}{n}\right) / 2}} .
\end{aligned}
$$

ParFlow also applies the two-dimensional kinematic wave equation as an overland flow boundary condition, and Manning's equation establishes flow depthdischarge relationships for surface runoff. The model simulates subsurface flow by solving the groundwater flow equation in space, using a cell-centered finite difference scheme, and in time, using an implicit backward Euler scheme. Studies have demonstrated ParFlow's ability to resolve very tight coupling between subsurface and surface hydrologic regimes (Kollet and Maxwell 2006, 2008; Maxwell 2013; Maxwell and Kollet 2008b), and $\mathrm{PFWRF}_{3 \mathrm{D}}$ extends groundwater-surface water coupling to the atmosphere. The primary source of coupling between ParFlow and Noah LSM is the $q_{r}$ term in Eq. (4), which represents the boundary condition and general source-sink to the top four soil layers. In the top soil layer, $q_{r}$ is given as $q_{r}(x, z)=P(x)-E(x)$ for precipitation $P$ and direct evaporation from the soil $E$, while in deeper layers from two through four, $q_{r}(x, z)=T(x, z)$ represents the transpiration flux $T$ in the root zone. Further information regarding coupling between ParFlow, Noah LSM, and WRF may be found in Maxwell et al. (2011), and detail on governing equations of energy, momentum, and moisture at the surface and lower atmosphere is given in Chen and Dudhia (2001). Note that while PFWRF FD simulates infiltration and flow in the vertical soil column using
Eqs. (4)-(7), lateral flow has been removed and redistribution of subsurface moisture is entirely one dimensional.

\section{c. Region of interest and model domain configuration}

Land surface models have been shown to overestimate soil moisture in ridges relative to valleys as a direct result of vertical-only soil water redistribution (e.g., Anyah et al. 2008; Soulis et al. 2000), and this is especially true in regions of primarily orographic precipitation. For this experiment, the four models were compared over a small study domain in the Rocky Mountain headwaters of Colorado, in order to capture relative sensitivities of surface and lower atmosphere states to moisture redistribution in a complex terrain setting. Figure 2 shows the configured domain, terrain, major cities and HUC8 (USGS hydrologic unit code) outlines, land classification, and permeability of soil and geologic units. This is a topographically intricate, semiarid region characterized by elevation-dependent rainfall and an annual hydrograph heavily influenced by snowpack and melt. The primary Colorado Headwaters, Blue, and Eagle Watersheds serve as the initial source of water to the Upper Colorado River basin, and Clear Creek to the west is a headwater contributor to the South Platte River (Fig. 2). These waters provide municipal and agricultural resources to over $30 \mathrm{mil}-$ lion people (Christensen et al. 2004; Ficklin et al. 2013). Prevailing winds blow from the west, but locally strong and divergent wind patterns can occur when the mountain terrain can funnel wind through valleys. Precipitation drivers are primarily orographic, with storms initiating through upslope advection, which destabilizes the atmospheric boundary layer by lifting air to saturation. It is also often the case that leeside boundary layer convergent zones form downwind of mountain ridges, influenced by the opposing hillslope, leading to cumulus initiation (Banta 1984).

PFWRF $_{3 \mathrm{D}}$ has previously been run over this model domain to diagnose hydrology-land-atmosphere coupling under land disturbance conditions (Forrester et al. 2018), with results suggesting that the energy and moisture flux sensitivity to widespread forest mortality is highly dependent on antecedent moisture conditions. This study uses the same atmospheric initial and boundary conditions and static soil, geology, and land use variables detailed in Forrester et al. (2018). While they provide a complete description of the model configuration and development, we provide a brief summary here.

Initial and boundary atmospheric conditions for WRF were supplied by the National Centers for Environmental Protection Global Forecast System (Final) (NCEP GFS-FNL) archive of global gridded 

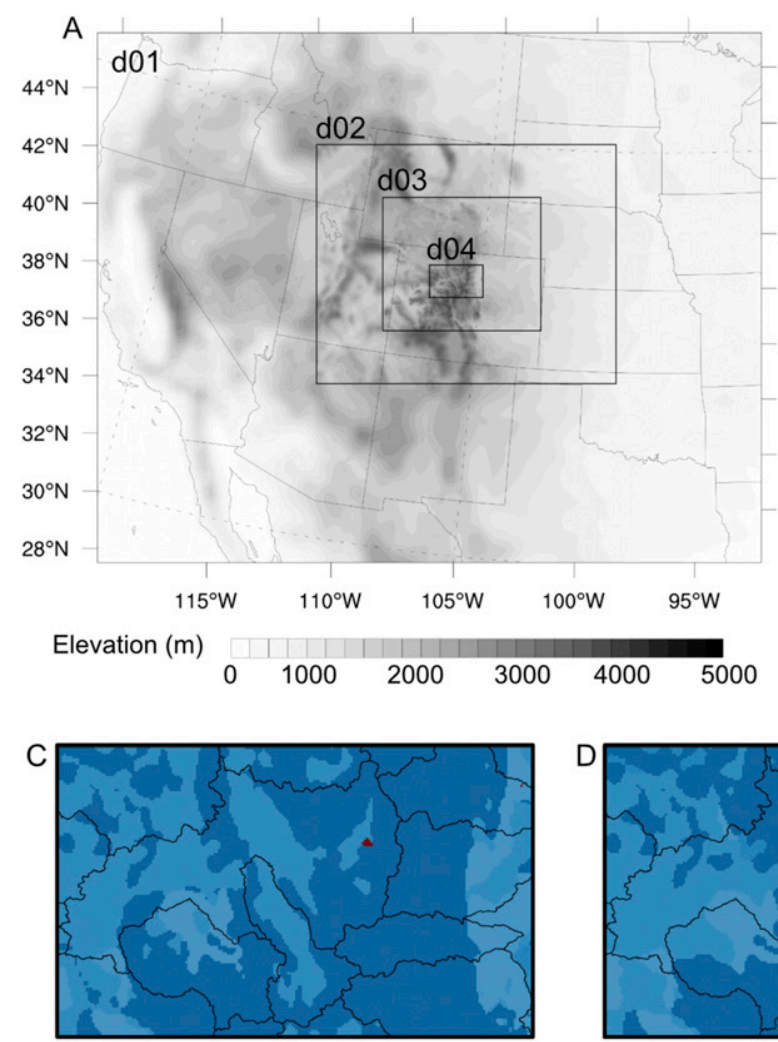

Permeability, $\log _{10}\left(\mathrm{~m} \mathrm{hr}^{-1}\right)$

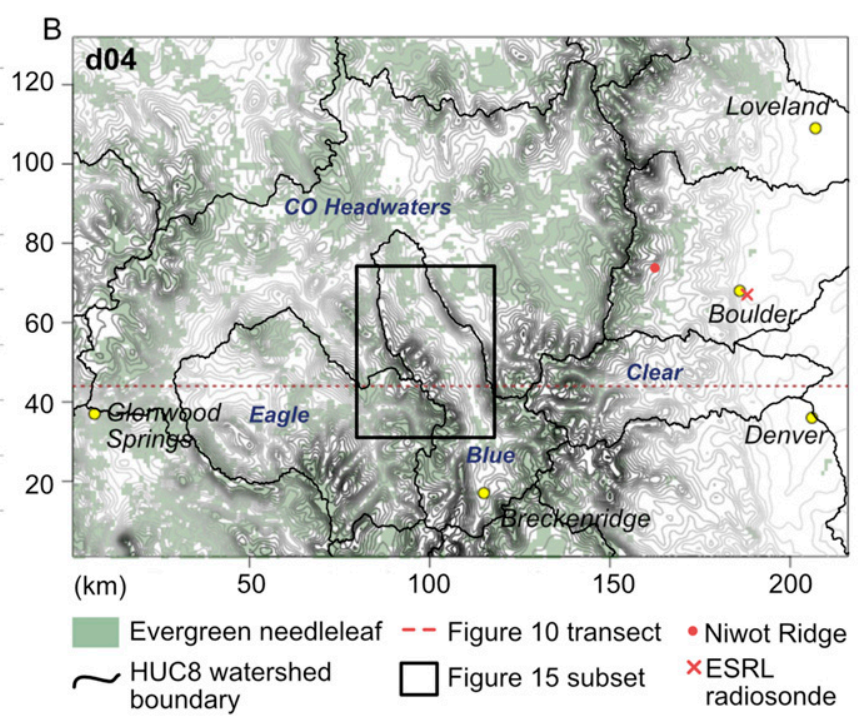

FIG. 2. (a) Nested domains for the WRF-only nested simulation to provide initial and boundary atmospheric conditions for d04. (b) Innermost d04 nest, primary model domain, with cities, watershed boundaries, and primary land cover class (evergreen needleleaf). (c)-(e) Permeability in the top soil layer, lower three soil layers, and lowest geologic layers, respectively. For clarity, only the primary land cover class is shown, covering $34.2 \%$ of model land area; other most common land classes are savanna (25.4\%), shrubland (12.4\%), grassland $(11.2 \%)$, and deciduous broadleaf $(6.7 \%)$.

analysis products (NOAA/NCEP 2000). These data products, at a $0.25^{\circ} \times 0.25^{\circ}$ grid and provided at 26 pressure levels ranging from 1000 to $10 \mathrm{mb}(1 \mathrm{mb}=1 \mathrm{hPa})$, were downscaled using one-way nested dynamic downscaling. The four nested domains, with grid cell spacing of 27, 9, 3, and $1 \mathrm{~km}$, are shown in Fig. 2. All further figures are for the innermost domain, d04, at 1-km lateral resolution. Simulations ran from 12 April through 30 August 2008. Dynamic downscaling was conducted with WRF (not coupled to ParFlow) using physics schemes detailed above in section $2 b$, and employing the Kain-Fritsch cumulus physics scheme for the coarsest scale (d01) domain (Kain 2004), in order to provide initial and boundary atmospheric conditions for the domain of interest (d01). Dynamic downscaling was conducted using an adaptive time step and solved over 27 meteorological layers. Land use and vegetation parameters were taken from the USGS 24-class land cover for Noah LSM, and products from the Snow Data Assimilation System (SNODAS) were used as the initial snowpack conditions for 12 April (National
Operational Hydrologic Remote Sensing Center 2004). Soils range from sandy to clay loams, and hydraulic properties for soil hydrofacies were supplied by the Soil Survey Geographic Database (SSURGO; Soil Survey Staff 2019) and from Schaap and Leij (1998). These soils are sourced from Permian and Carboniferous sedimentary bedrock in the Front Range and from primarily Precambrian metamorphic rocks in the mountains. Soil classes are consistent between WRF, WRF $\mathrm{WFIC}_{\text {, }}$ PFWRF $_{F D}$, and PFWRF $_{3 D}$; however, PFWRF $F$ and $\mathrm{PFWRF}_{3 \mathrm{D}}$ also require hydraulic properties for their deeper geologic units. These geologic unit classes were subset from a continental-scale, integrated hydrologic simulation of ParFlow (Maxwell et al. 2015), which used a continental-scale geologic permeability map adapted from Gleeson et al. (2011a).

As described above, initial subsurface moisture conditions for WRF were supplied by the WRF Preprocessing System (WPS) and the FNL forcing products, in which the top soil layer is at or near field capacity for most of the 
domain; in order to keep the free-drainage experiment as close in initial condition to the control as possible, PFWRF $_{\mathrm{FD}}$ was initialized with saturated soil moisture conditions and a surface-level groundwater table. However, PFWRF 3 D and $\mathrm{WRF}_{\text {PFIC }}$ were both initialized with a hydrologic spinup of the ParFlow model domain (Forrester et al. 2018), which was conducted by running the hydrologic model with repeated annual forcing from the North American Land Data Assimilation System (NLDAS; Cosgrove 2003), until the change in subsurface storage was within one percent of the annual forcing from one year to the next. Such a spinup method avoids initial moisture condition bias, as it supplies an equilibrium hydrologic state and reduces the tendency for artificial drift (Ajami et al. 2014). The spun-up pressure in all five model subsurface layers was used as the initial condition for PFWRF $\mathrm{FD}_{\mathrm{FD}}$ and PFWRF $\mathrm{PD}_{3 \mathrm{D}}$ on 12 April, while $W F_{\text {PFIC }}$ received only the soil moisture (calculated from ParFlow's simulated pressure head) in its four soil layers. The period from 12 April to 1 May was treated as an additional spinup of the coupled hydrometeorological system, and only results after 1 May are analyzed here. Monthly soil moisture conditions in the top soil layer are shown in Fig. 7 for all four models.

\section{d. Comparisons to observations}

Models were compared to observations at the Niwot Ridge AmeriFlux site in order to assess performance in land surface energy and atmospheric states. The Niwot Ridge AmeriFlux site is located on Arapahoe Moraine near Nederland, Colorado, between the Continental Divide (approximately $8 \mathrm{~km}$ to the west) and the beginning of the Great Plains ( $25 \mathrm{~km}$ to the east) (Blanken U.S.-NR1). The tower is situated at 3050-m elevation within a subalpine forest composed of subalpine fir, lodgepole pine, and Engelmann spruce (Monson et al. 2002). Prevailing winds from the west flow down the gently dipping $5^{\circ}-7^{\circ}$ slopes during most of the year; however, thermally induced valley-mountain winds from the east occur during many summertime days, and larger synoptic systems can also cause upslope winds (Turnipseed et al. 2004). Mean annual temperature is $4^{\circ} \mathrm{C}$, and mean annual precipitation is $800 \mathrm{~mm}$ (Monson et al. 2002). The 26-m-tall tower provides measurements including (but not limited to) wind speed and direction (measured by helicoid propeller anemometers and sonic anemometry), relative humidity, barometric pressure, precipitation (the heated tipping-bucket rain gauge is rated for temperatures between $-20^{\circ}$ and $50^{\circ} \mathrm{C}$ ), and surface turbulent fluxes (calculated from methods detailed in Webb et al. 1980) (Burns et al. 2016). We compared these measurements to modeled values from the adjacent model cell that was closest in elevation to the tower location. The corresponding model cell center is within the fetch of the prevailing winds (between 1.23 and $3.2 \mathrm{~km}$, depending upon stability conditions; Monson et al. 2002), and within $7 \mathrm{~m}$ of the site elevation. An Earth System Research Laboratory (ESRL) Global Monitoring Division radiosonde location was also used to compare to modeled boundary layer structure over Boulder, Colorado. These radiosonde observations were obtained through balloon flights carrying ozonesonde telemeters which measure temperature, pressure, and humidity.

\section{Results}

\section{a. WRF comparisons to observed meteorology}

WRF simulations were compared to available meteorological observations to provide confidence that the models can appropriately reproduce regional atmospheric conditions and behavior. As a caveat to model performance results, it is important to consider scale discrepancies between point observations and predicted values at individual 1-km model cells. We do not intend to identify one of the four model configurations as the best performing model. Further, results from the tested models at a single grid cell are not meant to evaluate model sensitivity to soil physics, since differences at a single point will be impacted by noisy, nonlocal atmospheric and subsurface processes. Rather, the AmeriFlux and ESRL observations are used to confirm that WRF Model configurations described in this study capture large scale trends, demonstrate appropriate magnitude of meteorological variables, and represent a realistic physical system appropriate for sensitivity studies of this kind. Comparisons between modeled daily near-surface meteorological states (including air temperature, relative humidity, air pressure, and surface turbulent fluxes) and those observed at the Niwot Ridge AmeriFlux site are shown in Fig. 3. Performance statistics shown in Fig. 3 are Spearman's rank-order correlation [Eq. (9)], which is a nonparametric measure of both strength and direction, while mean bias error for each meteorological variable is also discussed below. Because performance varies seasonally, performance metrics are reported for the whole simulation period, as well as for only days following 1 July.

The four models perform similarly for air temperature, pressure, and relative humidity (Fig. 3). General trends in atmospheric states are captured, with the following mean absolute error: modeled air temperature is $1.3^{\circ} \mathrm{C}$ higher after $1 \mathrm{July}$ and $0.4^{\circ} \mathrm{C}$ lower before 1 July than observed values; modeled relative humidity is $14.7 \%$ lower than observed over the simulation period; and modeled and simulated barometric pressure are 

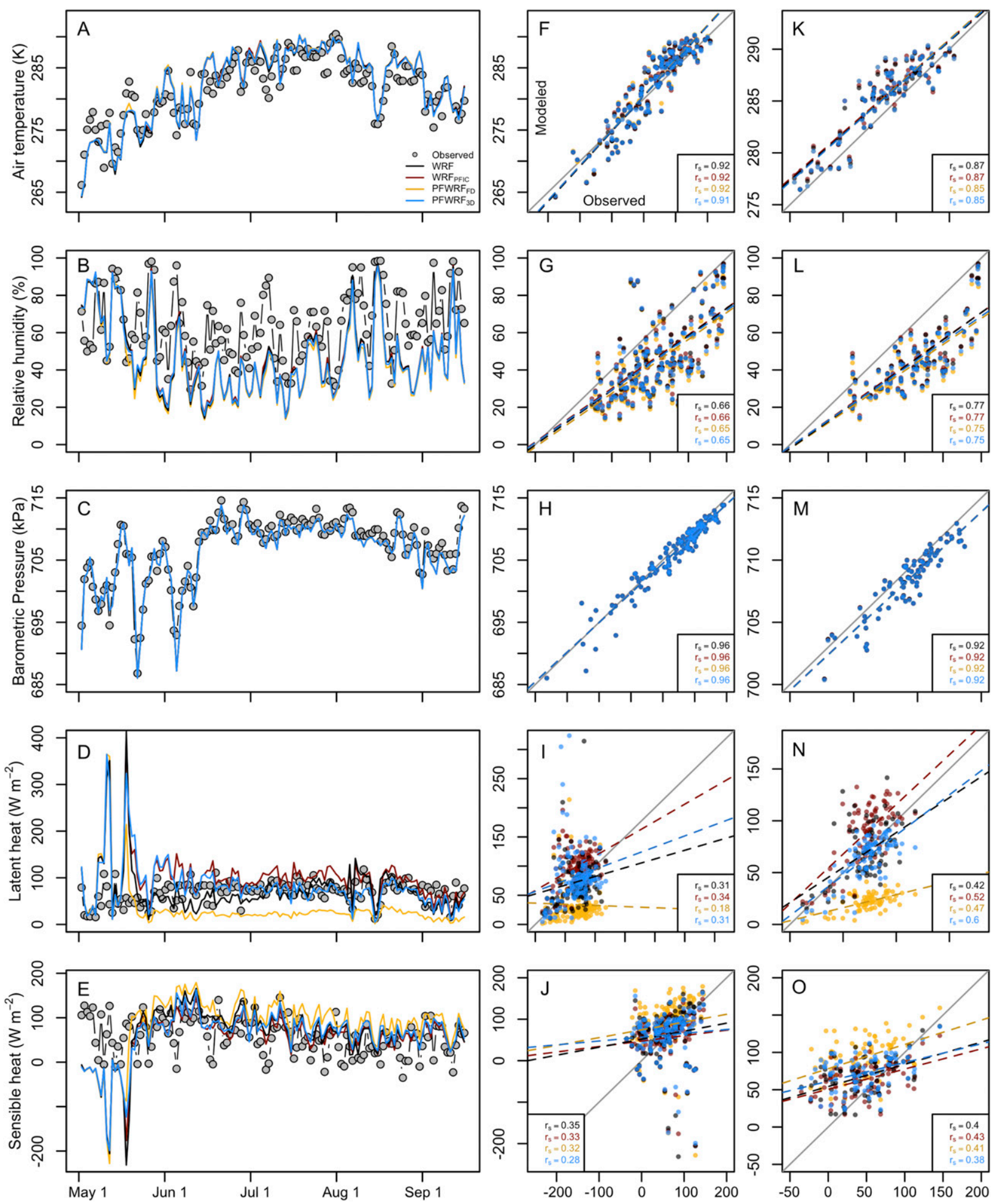

FIG. 3. Modeled and observed atmospheric states at the Niwot Ridge AmeriFlux site. (a)-(e) Daily time series for air temperature, relative humidity, barometric pressure, latent heat and sensible heat. (f)-(j) Modeled vs observed values for the entire time series, and (k)-(o) modeled vs observed values for daily time series after $1 \mathrm{Jul}$. Spearman rank correlation between simulated and observed values are shown for each scatterplot. 

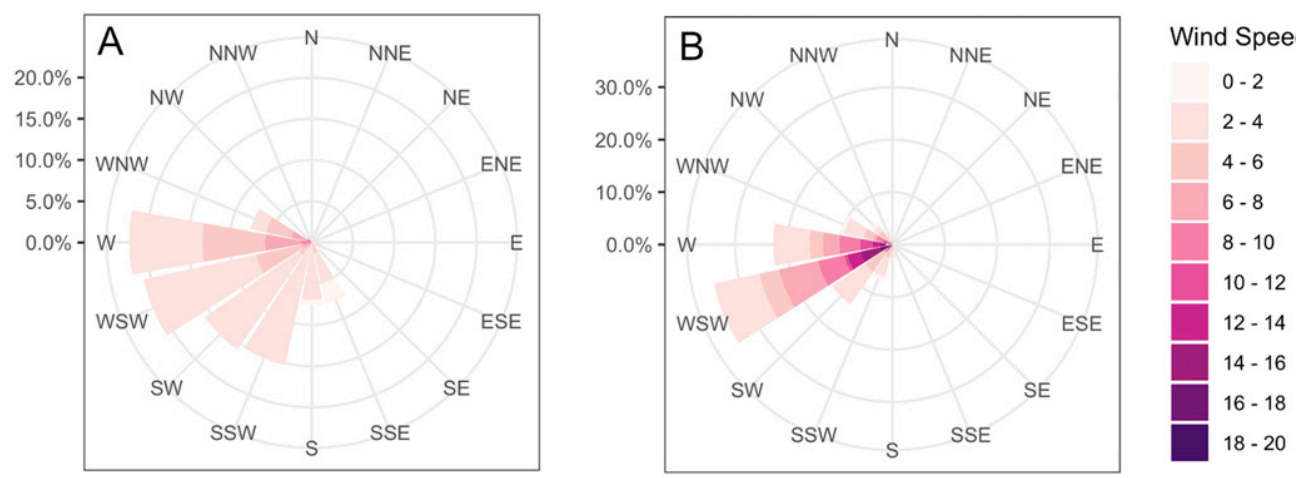

FIG. 4. Wind roses at the Niwot Ridge AmeriFlux location for (a) measurements and (b) the WRF baseline model. Wind roses for $\mathrm{PFWRF}_{\mathrm{FD}}, \mathrm{PFWRF}_{3 \mathrm{D}}$, and $\mathrm{WRF}_{\mathrm{PFIC}}$ are comparable to those of WRF and are not shown.

within $0.5 \mathrm{kPa}$ over the simulation period. Major differences can be seen in model performance for turbulent fluxes at the Niwot Ridge AmeriFlux location. For days following 1 July, models show total biases of -2.5 (WRF), -7.7 ( PFWRF $\left._{3 \mathrm{D}}\right), 16.9\left(\mathrm{WRF}_{\text {PFIC }}\right)$, and -50.8 $\left(\mathrm{PFWRF}_{\mathrm{FD}}\right) \mathrm{W} \mathrm{m}^{-2}$ for daily latent heat; mean absolute errors for sensible heat are $17.6\left(\mathrm{WRF}_{\mathrm{PFIC}}\right)$, $22.4(\mathrm{WRF}), 27.3\left(\mathrm{PFWRF}_{3 \mathrm{D}}\right)$, and $47.6\left(\mathrm{PFWRF}_{\mathrm{FD}}\right)$. $\mathrm{PFWRF}_{3 \mathrm{D}}$ performance is best by Spearman's rankorder correlation metric for latent heat, but worst for sensible heat (Fig. 3). Models exhibit poor performance for latent and sensible heat during several warming events in May, during which latent heat (sensible heat) is inappropriately high (low) (Fig. 3). Negative sensible heat flux is not unrealistic on winter days in these regions, particularly given the frequent occurrence of temperature inversions and cold ponding immediately above snowpack in complex terrain (Whiteman et al. 1999), but in this case, all models greatly overestimate this effect. Excessive negative sensible heat flux and corresponding overestimation of snow ablation in the Noah land surface model has been attributed to a cold vegetation-snow layer (Chen et al. 2014). Differences between modeled and observed sensible and latent heat can be primarily attributed to the land cover type assigned to the model cell. The nearest neighbor comparison shown in Fig. 3 uses a model cell within fetch of the prevailing winds and within $7 \mathrm{~m}$ of the Niwot Ridge tower elevation; however, the land class index at this location is savanna, contrasting the fir and pine forest surrounding the AmeriFlux site. Changing the model comparison location to the nearest evergreen needleleaf cell ( $3 \mathrm{~km}$ away, approximately $100 \mathrm{~m}$ higher in elevation) considerably reduces error in May (e.g., $-1.1,-17.3,21$, and $-24.7 \mathrm{~W} \mathrm{~m}^{-2}$ mean latent heat bias for $\mathrm{WRF}, \mathrm{PFWRF}_{3 \mathrm{D}}, \mathrm{WRF}_{\mathrm{PFIC}}$, and $\mathrm{PFWRF}_{\mathrm{FD}}$, respectively), but results in lower Spearman rank correlation for the rest of the summer simulation period.
Comparisons between observed and modeled precipitation and wind speed are shown in Figs. 4 and 5. Wind roses for WRF and the Niwot Ridge tower are shown in Fig. 4; wind roses between WRF, PFWRF ${ }_{3 \mathrm{D}}$, WRF $_{\text {PFIC }}$, and PFWRF $F_{F D}$ were nearly identical, so only WRF is shown. Observed winds are on average west or west-southwest, and modeled are west-southwest; observed wind directions are more variable than modeled values, and mean observed and modeled wind speeds are 5.7 and $3.4 \mathrm{~m} \mathrm{~s}^{-1}$, respectively. The higher modeled wind speeds are a result of several synoptic events in which high wind speeds are overestimated by the WRF configurations; however, the most frequent winds blow between 3 and $4 \mathrm{~m} \mathrm{~s}^{-1}$ for both models and AmeriFlux observations. All models appropriately capture the timing of rainfall events at this location (Fig. 5a). Spearman rank coefficients range between 0.73 and 0.74 , and between 0.75 and 0.82 , for mean and maximum weekly precipitation, respectively. Mean absolute error is $-0.79,-0.81,-0.84$, and $-0.92 \mathrm{~mm}$ day $^{-1}$, for $\mathrm{PFWRF}_{3 \mathrm{D}}, \mathrm{WRF}, \mathrm{WRF}_{\mathrm{PFIC}}$, and $\mathrm{PFWRF}_{\mathrm{FD}}$, respectively. Snapshots of daytime modeled boundary layer structure have also been compared to radiosonde observations. Figure 6 shows simulated humidity and temperature profiles near Boulder, Colorado, along with observed conditions from an Earth System Research Laboratory radiosonde location.

\section{b. Simulated near-surface soil moisture redistribution and meteorological states}

Inaccurate estimates of moisture in the unsaturated zone can bias the calculation of atmospheric forecasts (e.g., Findell and Eltahir 2003; Pielke 2001; Braun and Schädler 2005), by corrupting the surface water balance and turbulent flux prediction. Similarly, in these experiments, perturbations to WRF-simulated surface and atmospheric conditions originate in the lower boundary. Section $3 b$ discusses the primary differences between 

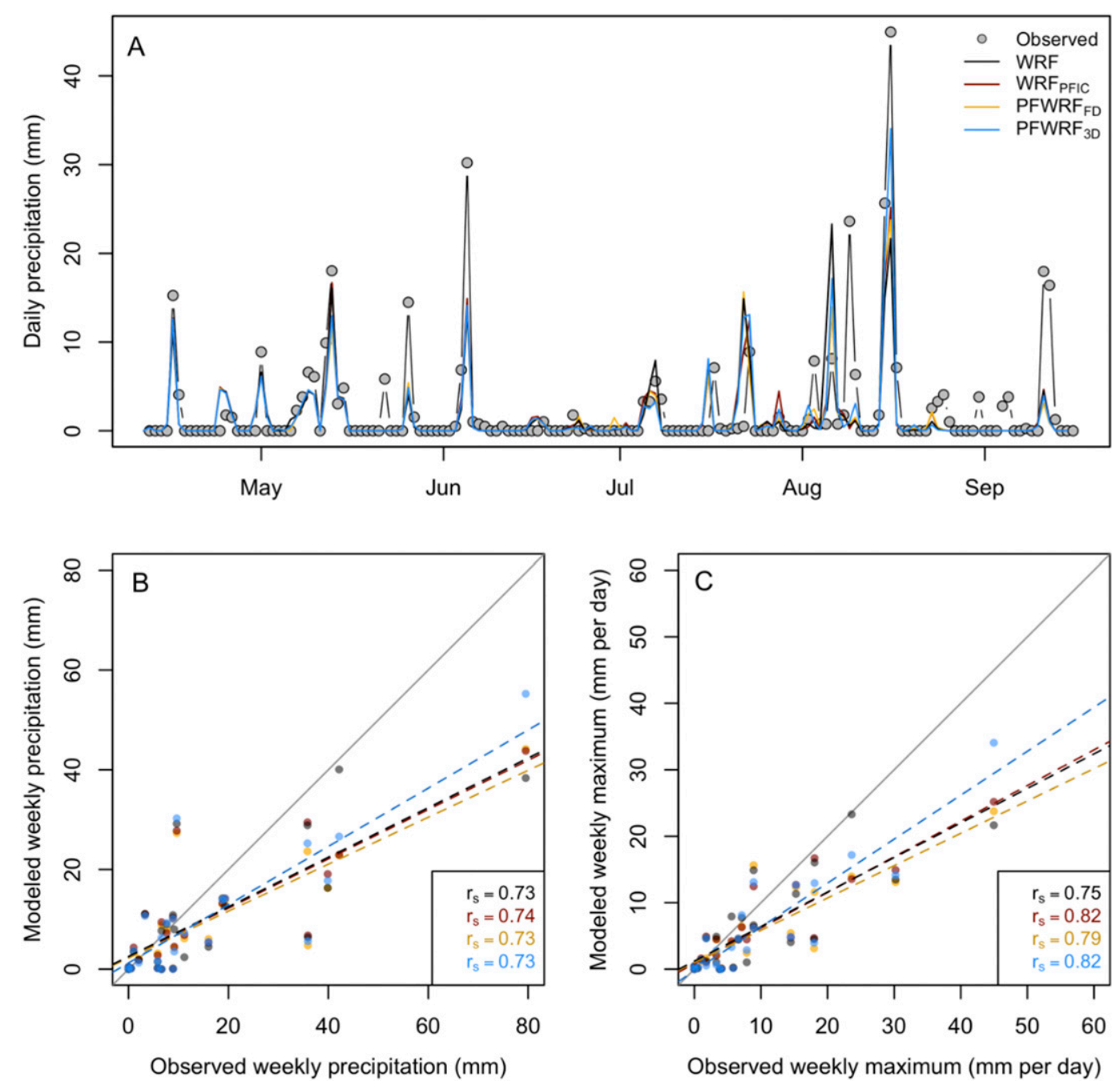

FIG. 5. (a) Observed and modeled daily precipitation at the Niwot Ridge AmeriFlux location. (b) Modeled vs observed weekly total precipitation. (c) Modeled vs observed weekly maximum precipitation event. Spearman correlation for each model is shown for weekly sum and maximum time series.

simulated soil moisture, surface turbulent fluxes, and planetary boundary layer height that are direct results of adjustments to WRF's lower boundary hydrologic scheme $\left(\mathrm{PFWRF}_{\mathrm{FD}}, \mathrm{PFWRF}_{3 \mathrm{D}}\right)$ or initial condition $\left(\mathrm{WRF}_{\mathrm{PFIC}}\right)$.

Figure 7 shows monthly averages of column-averaged volumetric soil moisture content for atmospheric models with differing terrestrial hydrology representation. Several comparisons can be made that highlight the relative influence of hydrologic initial condition, infiltration and drainage rates, and hydrologic model dimensionality on lower boundary moisture heterogeneity. WRF and $\mathrm{WRF}_{\mathrm{PFIC}}$ share lower boundary physics, including relaxing assumptions such as column-only flow, a shallow subsurface, and nonexistent groundwater or surface water routing. They differ only in their initial moisture condition, which in WRF's case was supplied by the WPS downscaling of meteorological products, and in WRF PFIC's by a ParFlow spinup to a hydrologic equilibrium state. Domain-wide initial moisture conditions supplied by the WRF Preprocessor are near field capacity in $\mathrm{WRF}_{\text {PFIC }}$ 's top model layer $(0.1 \mathrm{~m})$ on 12 April, while those supplied by ParFlow are highly heterogeneous, with higher soil moisture in topographic convergent zones and lower moisture in ridges. Columnaveraged $(0-2 \mathrm{~m})$ initial soil moisture is 0.26 and 0.22 for $\mathrm{WRF}_{\mathrm{PFIC}}$ and WRF, respectively. The hydrologic spinup's lateral routing signature is most evident in May, when $\mathrm{WRF}_{\mathrm{PFIC}}$ simulates higher (lower) soil moisture in valleys (ridges) relative to WRF (Fig. 7). The memory of

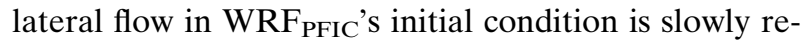
duced over time, with $\mathrm{WRF}_{\text {PFIC }}$ 's higher soil moisture maintained in convergent zones until August. 

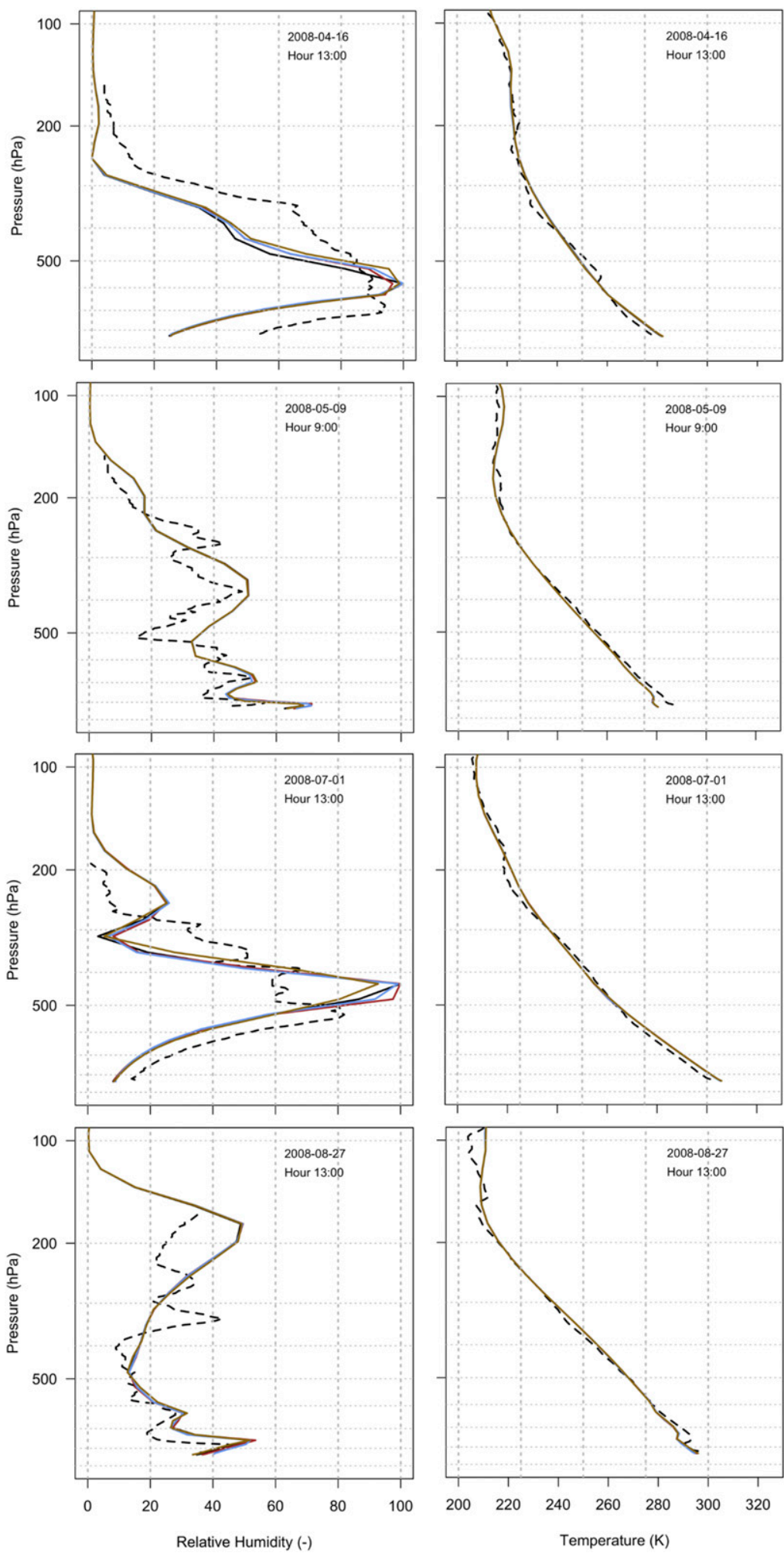

FIG. 6. Vertical structure of the convective boundary layer shown as (left) relative humidity and (right) temperature at various pressure levels. Four daytime profiles are given for the radiosonde location near Boulder, CO, shown in Fig. 2. Dotted lines are observed humidity profiles from the Earth System Research Laboratory Global Monitoring Division (ESRL/GMD), and solid lines are modeled values. Profiles are reported in local time. 

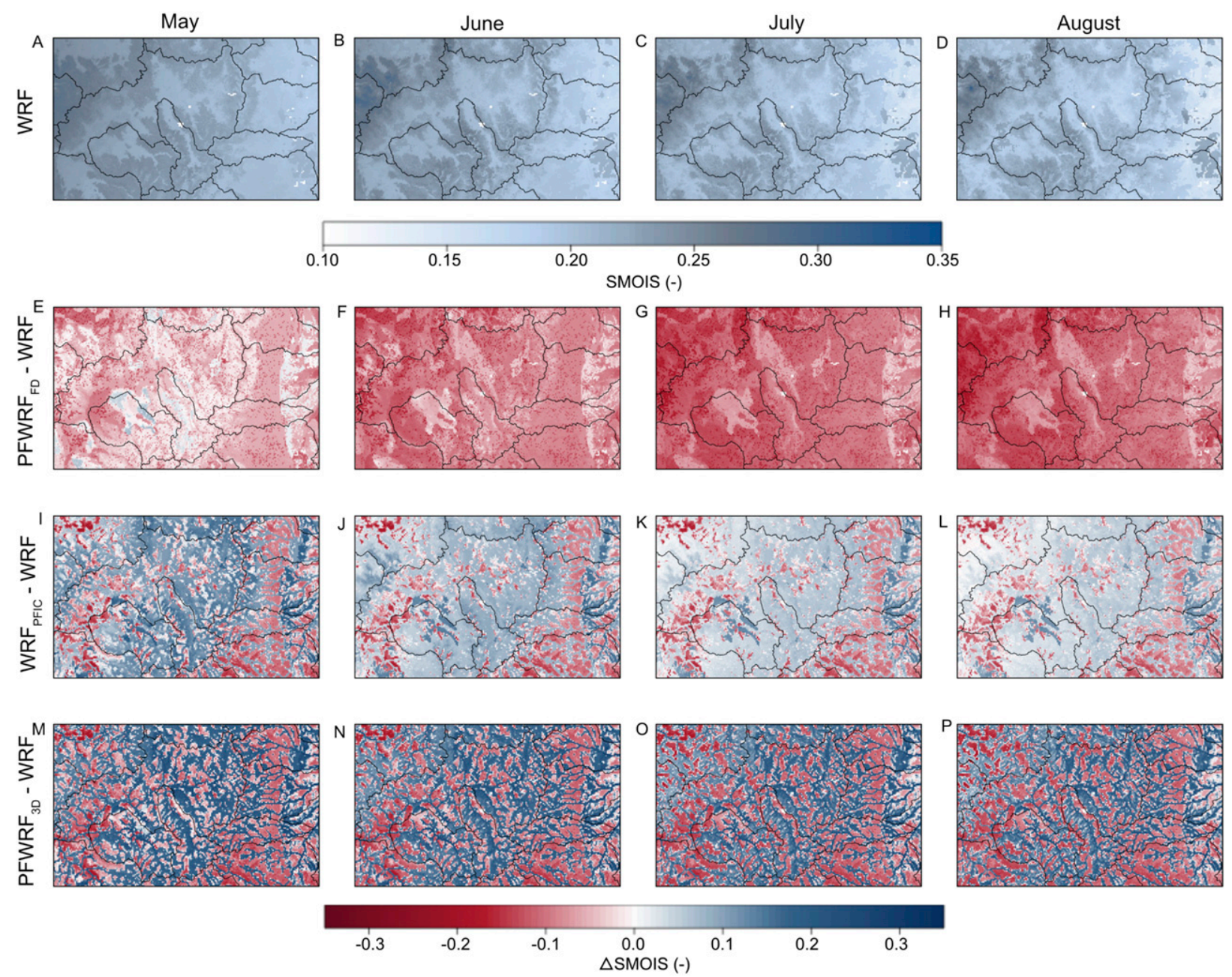

FIG. 7. (a)-(d) Monthly and column-averaged soil moisture over domain d04 for summer 2008; monthly difference in column averaged soil moisture between WRF and (e)-(h) PFWRF FD , (i)-(l) $\mathrm{WRF}_{\mathrm{PFIC}}$, and (m)-(p) PFWRF 3 .

WRF differs from PFWRF FD $_{\mathrm{F}}$ primarily in its infiltration schemes [see Eqs. (1)-(3) for Noah LSM and Eqs. (4)-(7) for ParFlow in section 2b] and lower boundary drainage. Both models share one-dimensional (vertical) soil column redistribution and complete removal of drained water from the subsurface. $\mathrm{PFWRF}_{\mathrm{FD}}$ exhibits significantly lower moisture in the soil column layer than WRF, which can largely be ascribed to soil hydraulic parameters: water infiltrates and drains more efficiently in the PFWRF $\mathrm{FD}_{\mathrm{F}}$ simulation, resulting in the largest reductions in soil moisture over the summer relative to other models. Notice that the difference between PFWRF FD $_{F}$ and WRF increases throughout the summer, as the region becomes less energy limited.

Unlike $\mathrm{WRF}_{\mathrm{PFIC}}$ or $\mathrm{PFWRF}_{\mathrm{FD}}$, which respectively decrease and increase in their difference from WRF through the summer, $\mathrm{PFWRF}_{3 \mathrm{D}}$ is temporally consistent in its distinction from WRF's simulated soil moisture
(Fig. 7). Some studies have suggested that the tendency for LSMs to remove water from the soil water balance through free-draining assumptions or saturation/infiltration excess runoff (e.g., Senatore et al. 2015; Yeh and Eltahir 2005), allows hydrologic models as lower boundary conditions (e.g., with deep, no-flow impermeable bedrock and the ability to reinfiltrate surface routed water) to retain more moisture in the soil column than LSMs. Throughout these simulations, despite evaporative drying of soils in an arid climate, PFWRF $_{3 \mathrm{D}}$ continues to route soil moisture laterally to maintain higher volumetric soil moisture in topographic convergence areas. Ridges in Noah LSM receive the highest amounts of orographic precipitation; in $\mathrm{PFWRF}_{3 \mathrm{D}}$, this recharge is routed to topographic lows, but PFWRF $F_{F D}, W R F$, and $W_{R F} F_{P F I C}$ can only route the water downward.

Spatial heterogeneity and dynamic redistribution of soil moisture in the lower boundary has an important 
impact on near-surface meteorological states. Surface turbulent fluxes, latent and sensible heat, are in particular strongly tied to the availability of soil moisture: Moisturelimited environments are characterized by high evaporative fraction, which is simply the portion of the surface turbulent flux dedicated to latent heating. Evaporative fraction is given as

$$
\mathrm{EF}=\frac{\lambda E}{\lambda E+H} .
$$

In (8), $\lambda E$ is latent heat, $H$ is sensible heat, and these quantities are traditionally summed during daylight hours when calculating daily evaporative fraction. High evaporative fraction implies a dominance of latent heating, which provides evaporative cooling and facilitates moist, cool boundary layer development. The opposite is true of low evaporative fraction. In general, higher evaporative fraction implies lower boundary layer height, if no other external drivers such as topography or synoptic systems are in play.

Figures 8 and 9 show WRF-simulated daytime evaporative fraction $(\mathrm{EF})$ and atmospheric boundary layer height (ABL, also known as planetary boundary layer height), respectively, along with the difference between WRF and simulations with adjusted hydrologic schemes. WRF evaporative fraction is highest during the spring and in regions characterized by evergreen needleleaf cells, likely influenced by late spring snowmelt and root zone transpiration (Fig. 8). Boundary layer height peaks in late June, but decreasing late summer temperatures and rising humidity and pressure (see, e.g., observations from Niwot Ridge AmeriFlux site in Figs. 3a-c) result in lower simulated boundary layer height in August. Differences in spatial patterns between WRF and PFWRF $\mathrm{PD}_{3 \mathrm{D}}$ are most obvious and easily explained. In valleys and streambeds, PFWRF $_{3 \mathrm{D}}$ increases soil moisture relative to WRF, while the opposite is true in ridges. Evaporative cooling increases EF in PFWRF $_{3 \mathrm{D}}$ valleys relative to WRF. The resulting cool, moist (warm, dry) air in topographic lows (highs) yields shallower (deeper) daytime atmospheric boundary layer. Similar patterns occur in the $\mathrm{WRF}_{\text {PFIC }}$ model, but as mentioned above, the initial condition pattern of streambed wetness has degraded considerably as lateral flow was not maintained. PFWRF $\mathrm{FD}_{\mathrm{FD}}$ experiences considerably lower $\mathrm{EF}$ and correspondingly higher $\mathrm{ABL}$ as a result of lower soil moisture; and, as in Fig. 7, the difference between $\mathrm{PFWRF}_{\mathrm{FD}^{-}}$and WRF-simulated atmospheric states increases throughout the summer (Figs. 9, 5e-h).

\section{c. The interaction between complex topography and hydrologic representation on land-atmosphere coupling}

Figures 7-9 show that the incorporation of lateral groundwater component in the lower boundary condition routes water to topographic lows, which promotes higher atmospheric boundary layer height in ridges and lower in valleys, relative to Noah LSM soil water configuration. The pattern of higher moisture yielding higher evaporative cooling and a subsequently lower boundary layer thickness is a pattern very well established in the literature (Santanello et al. 2009, 2011, 2015). In this section, we discuss how these impacts to boundary layer interact with local topography to affect regional drivers of land-atmosphere coupling, and in section $3 \mathrm{~d}$ we will discuss feedbacks to thermally driven flows and potentially regional precipitation patterns.

Topographic controls on atmospheric boundary layer development are shown in greater detail in an east-west topographic cross section (transect shown in Fig. 2), of soil moisture, surface skin temperature and atmospheric boundary layer height for all model configurations (Fig. 10). Notice that soil moisture in WRF clearly follows model elevation, while soil moisture in $\mathrm{PFWRF}_{3 \mathrm{D}}$ is highly variable, with the complex topography inducing steep gradients in soil moisture along slopes. If microtopography, slope aspect and slope magnitude were not factors, higher elevations should indeed have larger soil moisture values that persist through the summer given their higher relative precipitation, cooler temperatures and later snowmelt. However, given the influence of complex terrain on hydrologic flowpaths (Bachmair and Weiler 2011), topographic wetness index, upslope-accumulated area, or depth to water index may be more appropriate drivers to regional soil moisture heterogeneity and topographically sensitive soil-atmosphere exchange than elevation alone (e.g., Riveros-Iregui et al. 2012). Models have estimated that equilibrium water table depth in the Rockies is highly spatially heterogeneous, varying over multiple orders of magnitude (Fan et al. 2007; Gleeson et al. 2011b; Maxwell et al. 2011). Manning et al. (2013) estimated that for a $2.5-\mathrm{km}$ cross section across the continental divide, depth to the saturated zone varied from 0 to over $100 \mathrm{~m}$ in the two small bordering catchments; seasonal variations in water table depth were over $30 \mathrm{~m}$. We believe the steeper soil moisture gradients introduced by PFWRF $_{3 \mathrm{D}}$ may be physically representative of a region of high topographic complexity.

The relationship between ABL height and topography, in which higher elevations yield lower temperatures and lower ABL height, is dampened by the inclusion of lateral flow in $\mathrm{PFWRF}_{3 \mathrm{D}}$ (Figs. 10, 11), because EF becomes more sensitive to slope and topographic index than on elevation alone. Figure 11 shows atmospheric boundary layer height as a function of evaporative fraction for the four model configurations. Plotted are temporally averaged (for months May-August) daytime evaporative fraction and daytime atmospheric boundary 

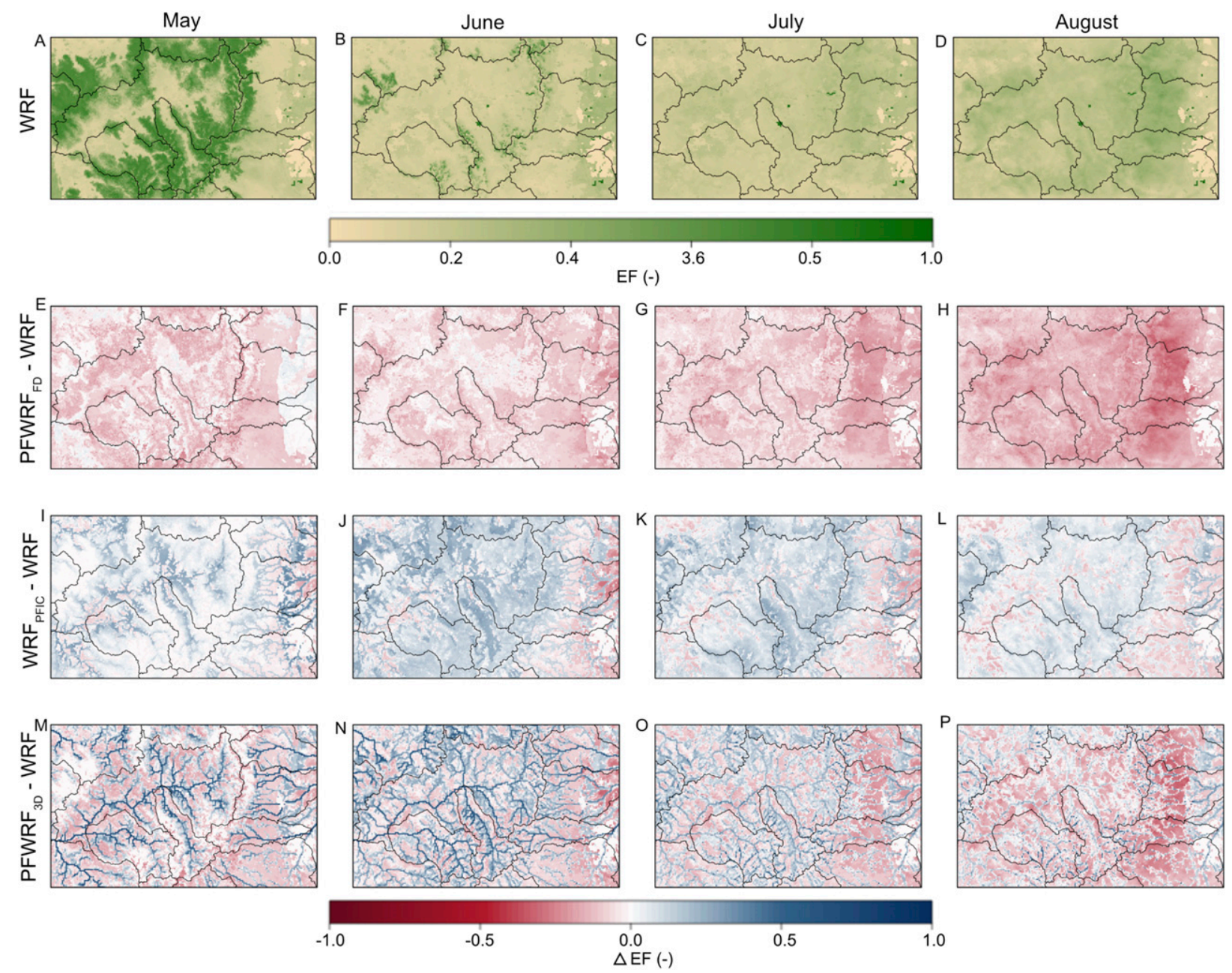

FIG. 8. (a)-(d) Monthly and column-averaged evaporative fraction over domain d04 for summer 2008; monthly difference in column averaged evaporative fraction between WRF and (e)-(h) PFWF $_{F D}$, (i)-(l) $\mathrm{WRF}_{\mathrm{PFIC}}$, and (m)-(p) PFWRF $\mathrm{PD}_{3 \mathrm{D}}$.

layer height; each point on the scatter represents a cell in the primary Colorado Headwaters Watershed (Fig. 2), and locally weighted scatterplot smoothing (LOWESS) has been added. Notice that PFWRF $3 \mathrm{D}$, and to a lesser extent $\mathrm{WRF}_{\mathrm{PFIC}}$, exhibits lower slope and greater scatter for the ABL-EF relation.

PFWRF $_{\mathrm{FD}}$ showed the largest relative differences in magnitude of surface energy and ABL height relative to the WRF baseline simulation (Figs. 7-9), as moisture is allowed to gravitationally drain from the lowest node based on conductivity alone, resulting in considerably less soil water content. Notice that while the overall magnitude of EF was most sensitive to the free-draining condition, the slope and variability of the ABL-EF relationship is maintained relative to the WRF baseline, indicating that a free-draining condition $\left(\mathrm{PFWRF}_{\mathrm{FD}}\right)$ maintains topographic controls on ABL surface moisture dependency (Fig. 11c).
We also explore the temporal, rather than spatial, dependence of boundary layer height on EF with Spearman's rank test, which is a nonparametric test given as

$$
r_{s}=1-\frac{6 \sum_{i=1}^{n} d_{i}^{2}}{n\left(n^{2}-1\right)} .
$$

The test was conducted to see if EF and boundary layer height time series, for a given cell, have similar shapes. In Eq. (9), then, $d_{i}$ is the independent ranking difference between daytime EF and boundary layer height time series at day $i$ and $n$ is the number of days in the simulation. Figure 12 shows the value of $r_{s}$ for each cell in the domain for the four model configurations. Blue regions indicate that trends in EF and boundary layer height were opposing predictors of one another, 

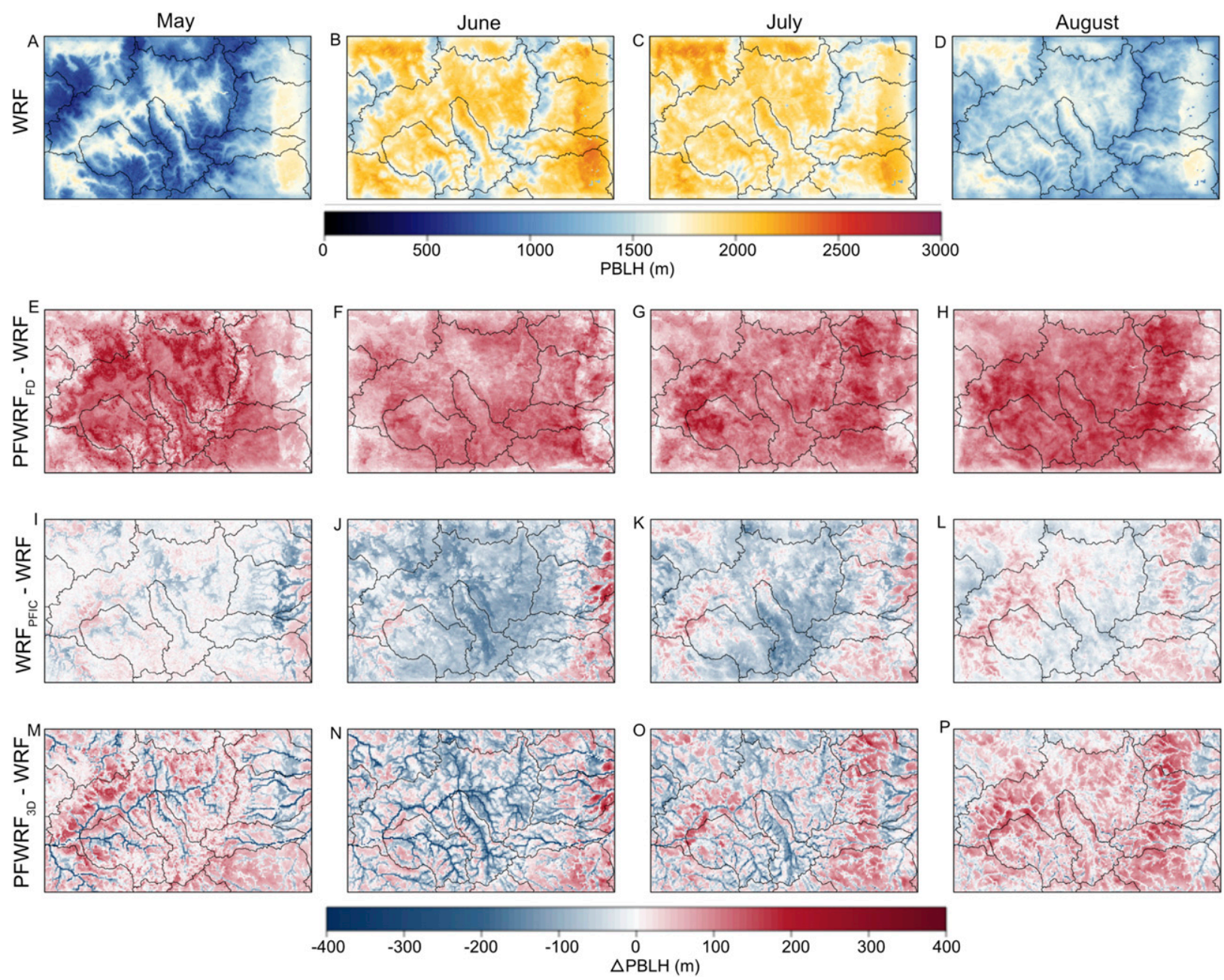

FIG. 9. (a)-(d) Monthly and column-averaged daytime planetary boundary layer height over domain d04 for summer 2008; monthly difference in column averaged daytime planetary boundary layer height between WRF and (e)-(h) PFWRF $F_{F D}$, (i) $-(1) W_{R F} F_{P F I C}$, and (m)-(p) PFWRF 3 D.

while red regions indicate that boundary layer development and evaporative fraction trended together. This latter instance (red) represents known EF controls on turbulent fluxes discussed above (Santanello et al. 2009); however, positive $r_{s}$ values may indicate that the same external forcing directly influenced both $\mathrm{EF}$ and the boundary layer. For example, in all models, EF and atmospheric boundary layer height trend positively along the east side of the Front Range, a region influenced by convective storm formation caused by boundary layer convergence on the leeward side of topographic highs. These convective storm events are responsible for large summertime precipitation events in the uppermost High Plains regions, and large storms can increase evaporative fraction by increased recharge.

Gray regions in Fig. 10 represent nonsignificant $r_{s}$ values $(p>0.05)$. Importantly, Fig. 10 suggests that not only does the PFWRF $\mathrm{PD}_{3 \mathrm{D}}$ hydrologic scheme increase the number of cells in which the EF-boundary layer correlation is insignificant, it can actually reverse the correlation of trends. This is the case for many cells within the Colorado Headwaters watershed, with Spearman's $r_{s}$ shifting from negative (expected) to positive. This has implications for choice of hydrologic scheme and its control on averages and spatial patterns of lower atmosphere states (e.g., Figure 4), but it also implies that lower boundary representation and soil moisture redistribution methods can shift the direction of modeled land-atmosphere coupling mechanisms. Topographic convergence regions where the correlation is not statistically significant for $\mathrm{PFWRF}_{3 \mathrm{D}}$ may indicate that lateral flux from nonlocal regions (e.g., streamflow following snowmelt in June) changes EF timing and allows soil water to persist longer in the summer, constraining 

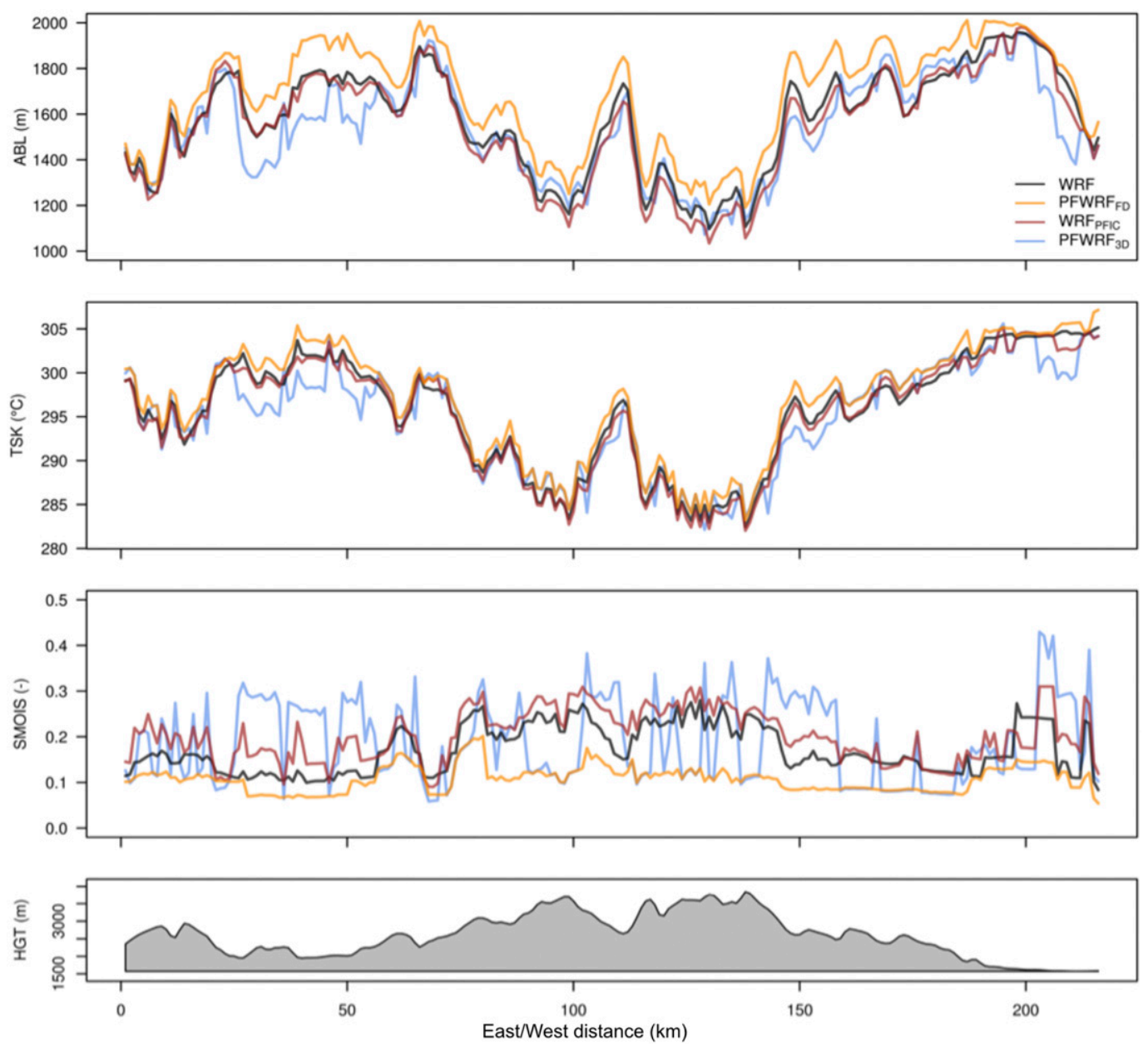

FIG. 10. Horizontal profiles of (top) modeled planetary boundary layer height, (top middle) surface skin temperature, (bottom middle) soil moisture, and (bottom) terrain height, along the cross section shown in Fig. 2. Values given for WRF (black), $\mathrm{WRF}_{\mathrm{PFIC}}$ (red), $\mathrm{PFWRF}_{\mathrm{FD}}$ (yellow), and $\mathrm{PFWRF}_{3 \mathrm{D}}$ (blue) model results.

moisture limitation. $\mathrm{WRF}_{\mathrm{PFIC}}$ shows some of these added regions where $\mathrm{EF}$ and $\mathrm{ABL}$ are not monotonically correlated. Also notice the similarities for some regions in red between $\mathrm{PFWRF}_{3 \mathrm{D}}$ and $\mathrm{PFWRF}_{\mathrm{FD}}$. In these regions, infiltration and drainage rate may play a more important role in $\mathrm{ABL}-\mathrm{EF}$ coupling relative to lateral routing.

\section{d. Feedbacks from subsurface hydrology to moist convection and anabatic flows}

Perturbations to land surface and atmospheric states propagate into regional patterns of wind and moisture caused by microtopography. In this section we address the influence of LSM hydrology on the diurnal cycle and on regional circulation and precipitation, suggesting two primary mechanisms for changes to rainfall events: upslope flows on warm summer days and moist convection in valleys.
Figures 13 and 14 show the development of the convective boundary layer during an average diurnal signal for the four model configurations. Shown are mean diurnal signals of specific humidity $Q$, potential temperature $\theta$, and vertical wind speed $W$, averaged over valleys (Fig. 13) and ridges (Fig. 14) west of the Continental Divide. Diurnal signals were averaged during the month of June due to the higher frequency of clear sky days relative to other months of the simulation. We define ridges and valleys in terms of groundwater convergence to discharge zones: Fig. 13 shows diurnal signals over grid cells containing major streambeds in the Colorado Headwaters, Blue, and Eagle Watersheds, while Fig. 14 subsets topographic local maxima with water table depths of at least $30 \mathrm{~m}$.

The grouping of June diurnal signals based on topographic convergence zones highlights differences in radiative convection development and mountain and 

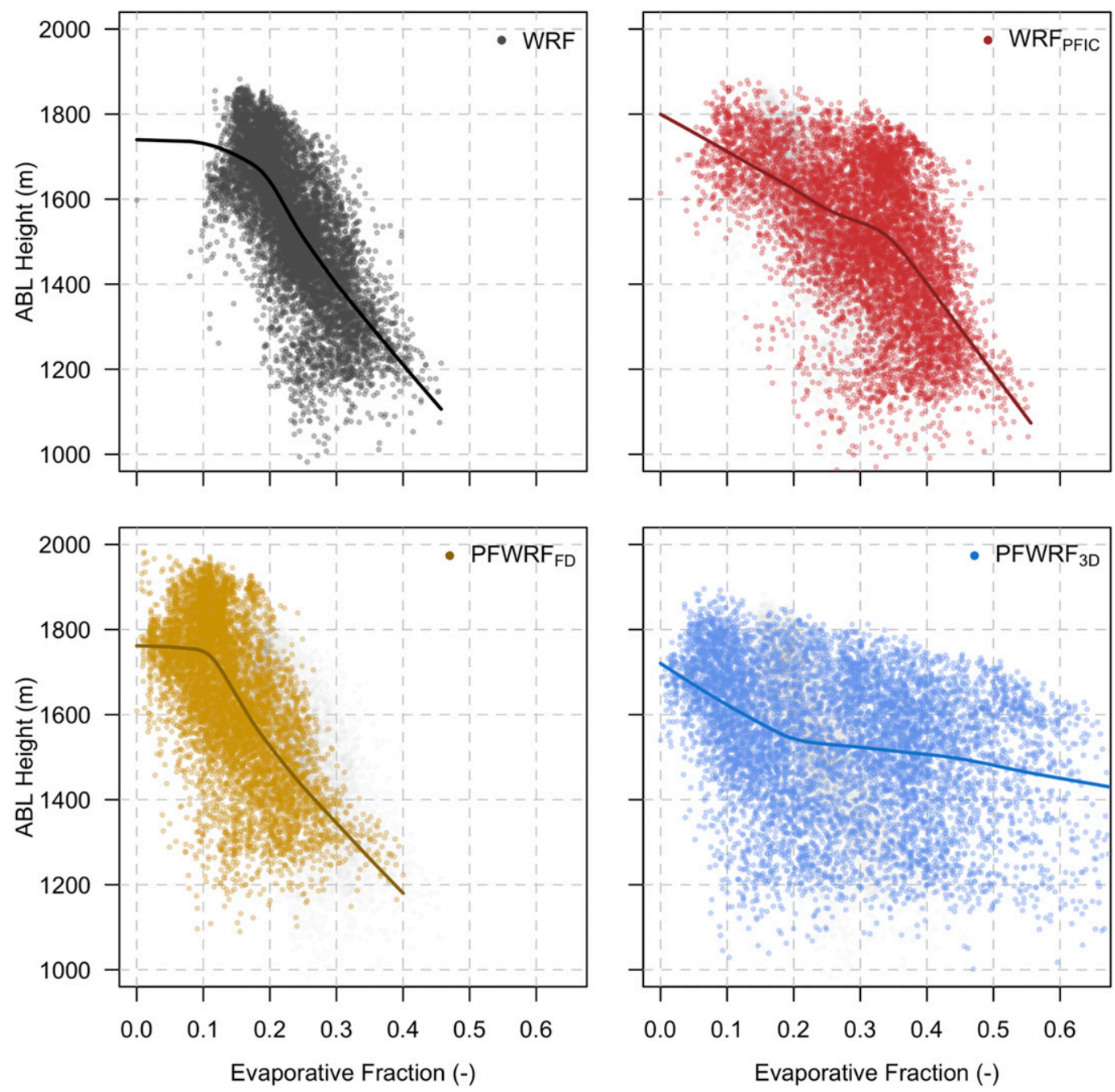

FIG. 11. Atmosphere boundary layer height as a function of evaporative fraction for four model configurations. Each point represents the temporal mean for a cell in the primary Colorado Headwaters watershed. The solid line represents LOWESS smoothing with a smoother span of $f=1 / 3$.

valley breezes. While maximum ABL height is over $200 \mathrm{~m}$ lower than valleys than ridges, the temporal development of WRF convective boundary layer height, humidity and temperature is similar in both locations, with boundary layer height peaking at approximately 1500 local time (LT; Figs. 13a,b, 14a,b). Ridges show a mountain and valley breeze signal, with daytime radiative heating causing upward (Fig. 14c). Daytime vertical wind speed over valleys is slower and characterized by downward movement in the lower convective layer (Fig. 13c). These anabatic mountain-valley circulations, typical systems of mesoscale thermal convection in the Rocky Mountains, occur when mountain slopes warm from radiative forcing, causing warm air to rise upslope, which eventually cools and sinks to collect in valleys (Defant 1951; Rampanelli et al. 2004).
Turnipseed et al. (2004) identify buoyancy-driven daytime upslope winds as a primary driver of regional atmospheric flow in this region, along with mountain gravity waves and strong wintertime winds.

For the PFWRF $F_{F D}$ (free draining) and $\mathrm{WRF}_{\mathrm{PFIC}}$ (hydrologic model initialized soil moisture) configurations, perturbations to humidity and temperature do not heavily depend on valley or ridge classification. PFWRF $_{F D}$ simulates lower humidity and higher temperatures than WRF, and these differences are most pronounced during the morning hours (1000-1100 LT), facilitating higher $\mathrm{ABL}$ height, especially around noon

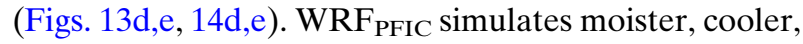
and lower ABL than WRF throughout the day, with differences peaking at 1400-1500h (Figs. 13g,h, 14g,h). Nighttime boundary layer is also impacted, with $\mathrm{WRF}_{\text {PFIC }}$ 

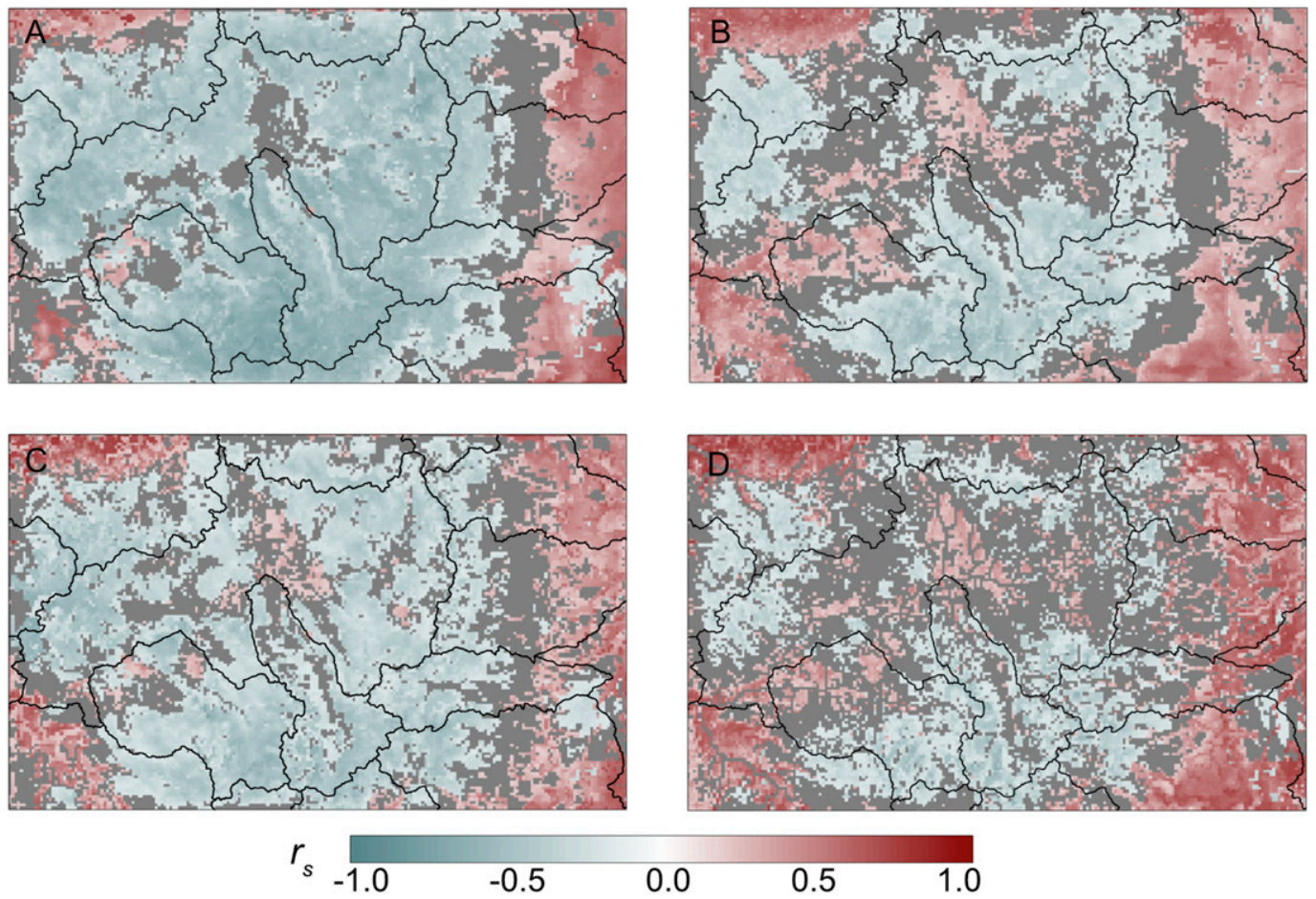

FIG. 12. Spearman's $r_{s}$ value for the correlation between atmospheric boundary layer height and evaporative fraction time series at every cell in the domain. Correlations were calculated using time series from 1 May through 31 Aug. Results from (a) WRF, (b) PFWRF FD , (c) $\mathrm{WRF}_{\mathrm{PFIC}}$, and (d) PFWRF $\mathrm{PD}_{3 \mathrm{D}}$. Blue colors represent opposing trends in shape, while red indicates time series that positively correlate. Gray regions represent nonsignificant values $(p>0.05)$.

exhibiting higher potential temperature, especially during the early morning hours (Figs. 13h, 14h). PFWRF $_{3 \mathrm{D}}$ shows similar behavior to $\mathrm{WRF}_{\mathrm{PFIC}}$, with a dramatic decrease in boundary layer height over valleys; however, changes to humidity, temperature and vertical wind speed are dampened over ridges. In a water-limited environment such as this, increased moisture availability in valley floors (a function of lateral groundwater transport and water table convergence) leads to a more efficient evaporative cooling than in ridges (Figs. 13j,k) for PFWRF $3 \mathrm{D}$. In June, the lateral routing scheme results in no significant change in mean boundary layer height over ridges (Figs. 9n, 14j), contrasting the more than 200-m decrease in ABL height over valleys relative to WRF (Fig. 13j).

Subsurface-driven perturbations to vertical winds suggest sensitivity of mountain-valley breeze patterns to soil moisture distributions. PFWRF $F_{\mathrm{FD}}$ simulates higher upward winds over ridges relative to WRF, a result of higher surface temperatures and rising eddies (Fig. 14f); however, the free-draining model shows noisy perturbations to vertical winds over valleys, likely dampened and more chaotic due to leeward valley turbulence. In valleys, both PFWRF $\mathrm{FD}_{3 \mathrm{D}}$ and $\mathrm{WRF}_{\mathrm{PFIC}}$ have reduced upward air movement compared to WRF, a function of cooler surface temperatures (Figs. 13i,k). However, unlike $\mathrm{WRF}_{\mathrm{PFIC}}, \mathrm{PFWRF}_{\mathrm{FD}}$ shows increased upward breezes above ridges during morning hours; such a combination could strengthen the morning development of mountain-valley circulation patterns.

These systematic changes in diurnal thermal regimes, vertical airflow, and spatial organization of surface moisture (Figs. 7-9) result in perturbations to regional convection and precipitation. Figure 15 shows differences in cumulative precipitation fields between the baseline WRF Model and PFWRF $F_{F D}, W F_{P F I C}$, and PFWRF $_{3 \mathrm{D}}$. Largest magnitude changes are focused on the leeward side of the continental divide for all four models, highlighting the sensitivity of solenoidal circulation, in which both thermally driven flows and horizontal convergence of the ABL drive convection over mountain ridges (Kirshbaum et al. 2018), to lower boundary condition hydrology. However, precipitation differences between model configurations and the WRF baseline are inconsistent not well organized. Below, we discuss possible and opposing forces driving increases or decreases in precipitation.

Moist orographic convection can occur when a saturated, rising air parcel accelerates away from its initial position, causing moist static instability. Figure $15 \mathrm{e}$ shows 

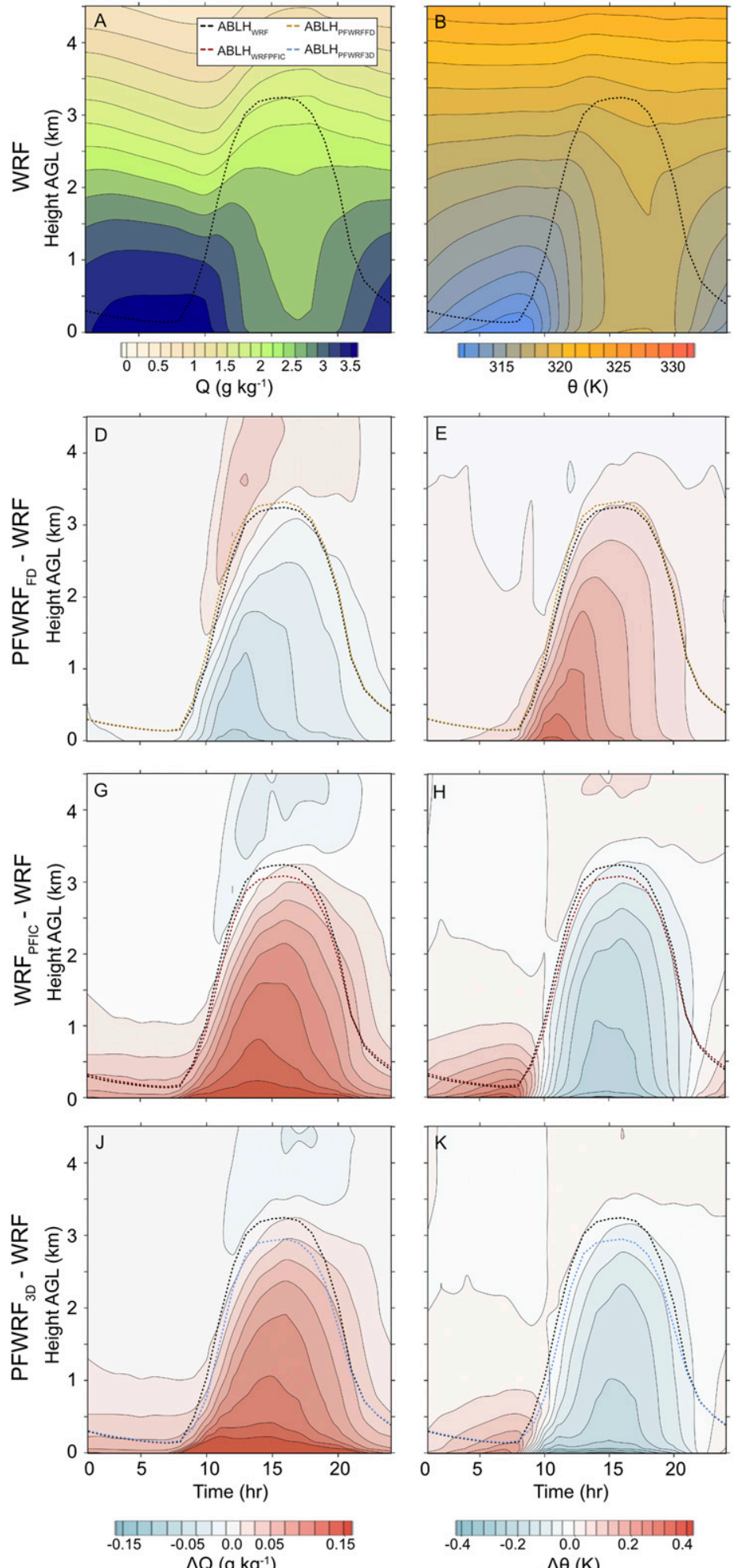
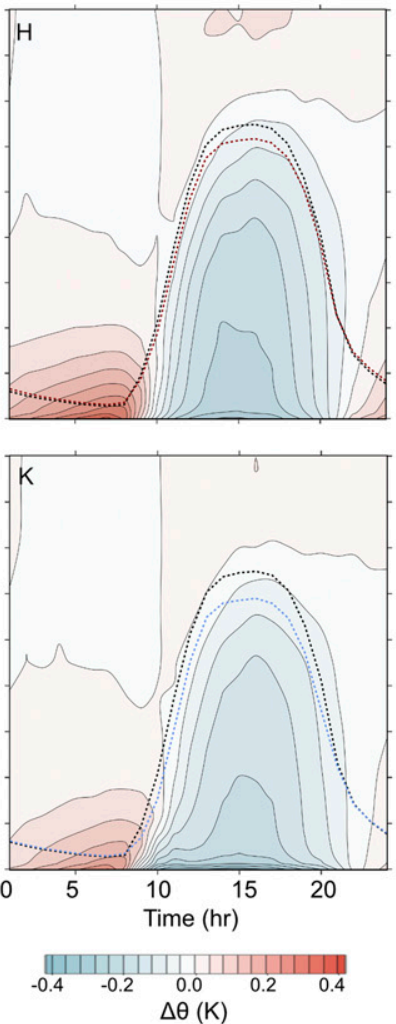
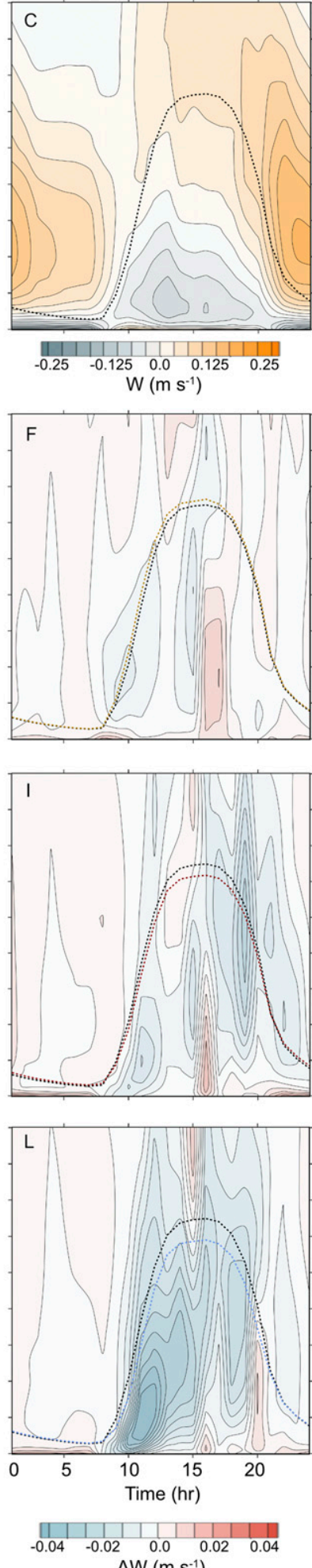

FIG. 13. Mean diurnal vertical profiles of (a) WRF-simulated humidity, (b) potential temperature, and (c) vertical wind speed, averaged spatially over valleys and temporally during the month of June. Difference

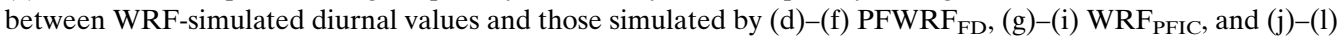
$\mathrm{PFWRF}_{3 \mathrm{D}}$. Diurnal cycles are shown in local time, such that hour 0 indicates 0700 UTC. 

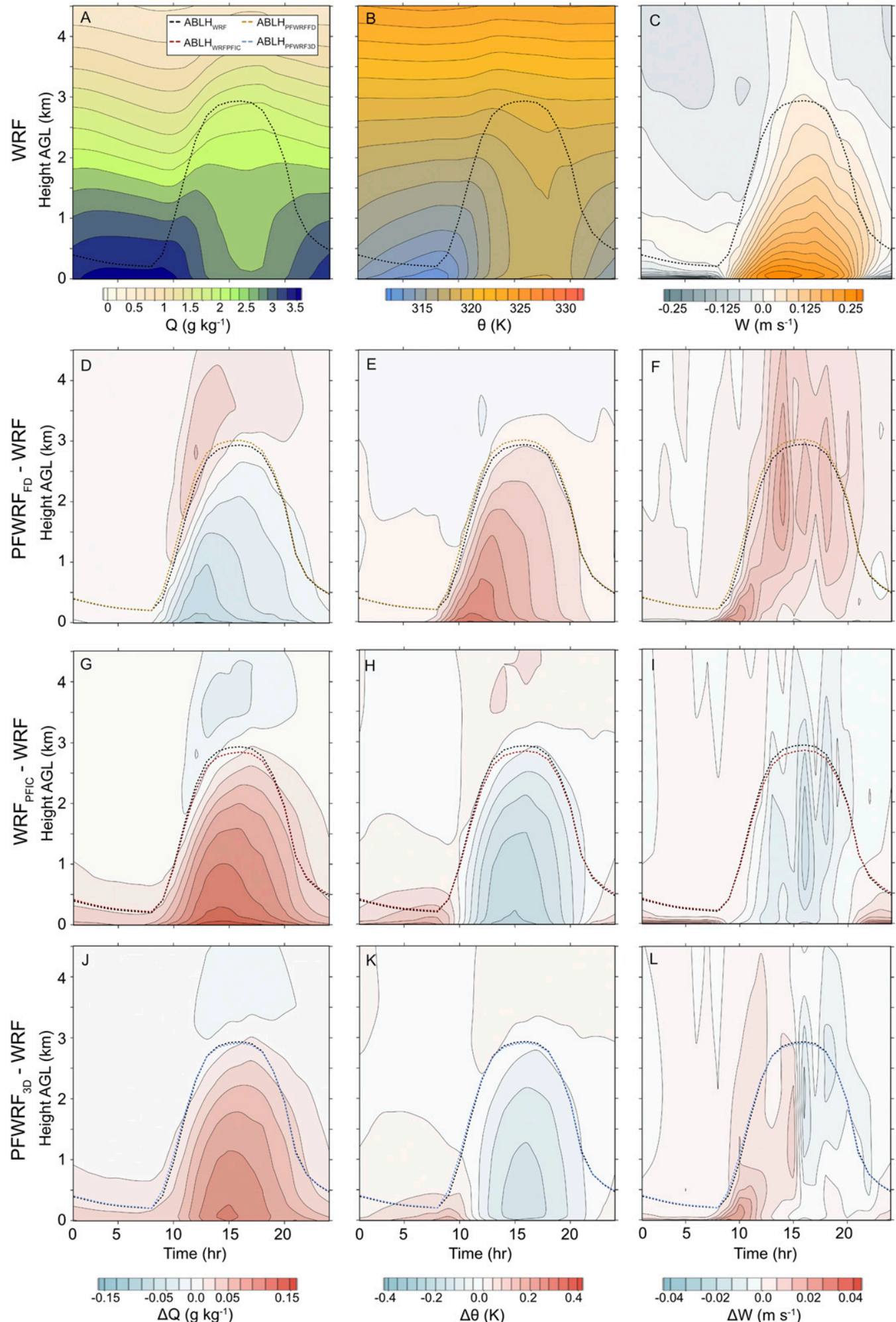

FIG. 14. Mean diurnal vertical profiles of (a) WRF-simulated humidity, (b) potential temperature, and (c) vertical wind speed, averaged spatially over ridges and temporally during the month of June. Difference

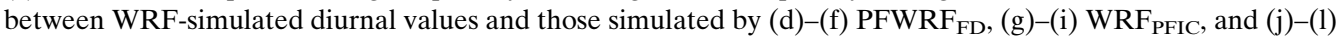
$\mathrm{PFWRF}_{3 \mathrm{D}}$. Diurnal cycles are shown in local time, such that hour 0 indicates 0700 UTC. 


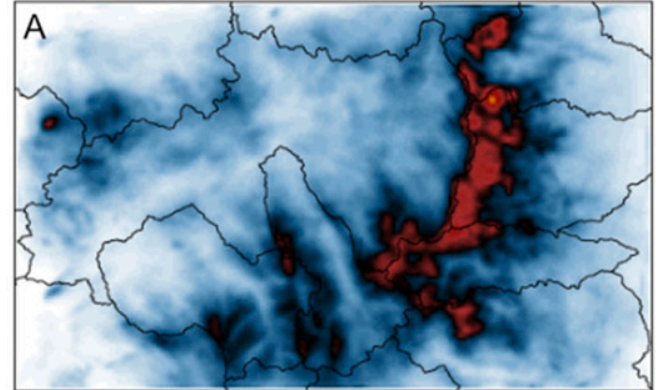

WRF cumulative precipitation $(\mathrm{mm})$

$\begin{array}{lllllllll}0 & 50 & 100 & 150 & 200 & 250 & 300 & 350 & 400\end{array}$

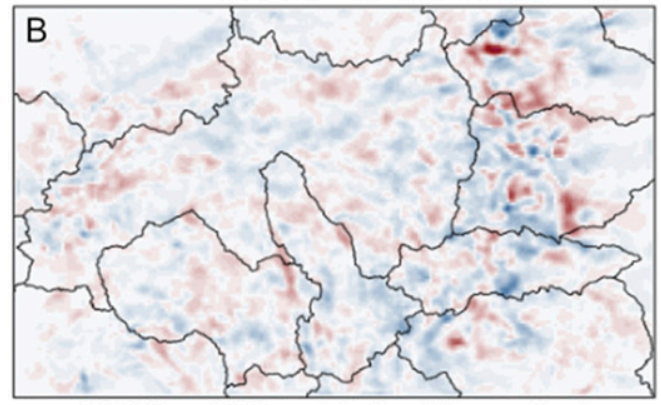

PFWRF $_{F D}-$ WRF precipitation difference $(\mathrm{mm})$

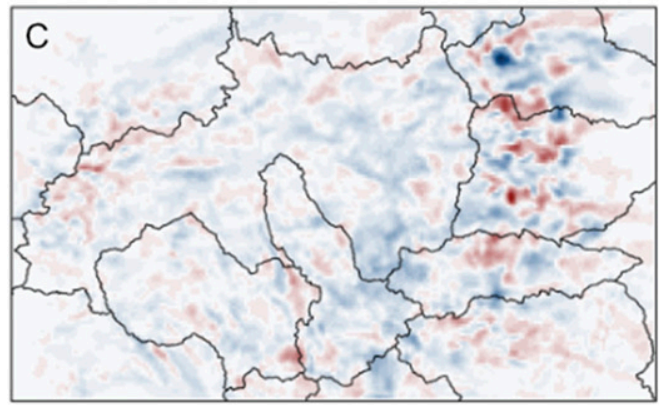

WRF $_{\text {PFIC }}$ - WRF precipitation difference $(\mathrm{mm})$

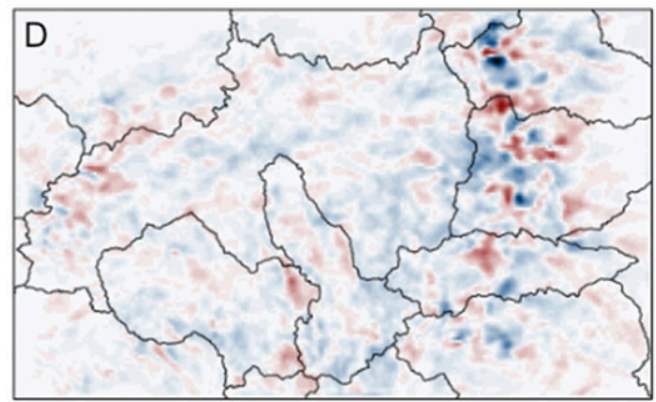

PFWRF $_{3 D}-$ WRF precipitation difference $(\mathrm{mm})$

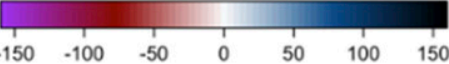

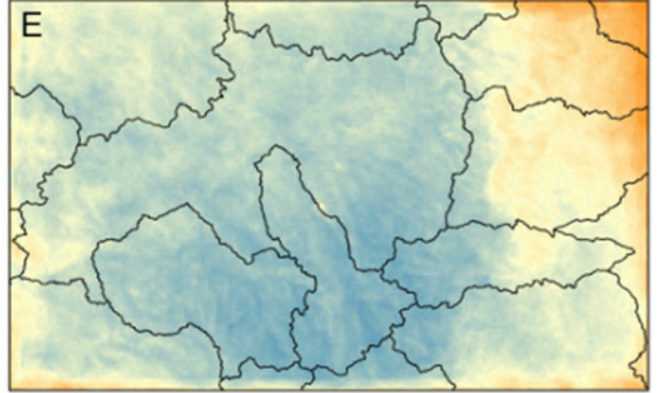

WRF MCAPE $\left(\mathrm{J} \mathrm{kg}^{-1}\right)$
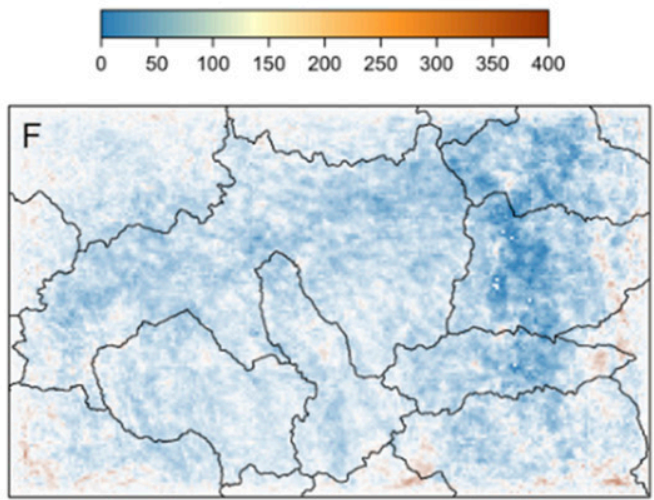

PFWRF $F$ - WRF mCAPE difference $\left(\mathrm{J} \mathrm{kg}^{-1}\right)$

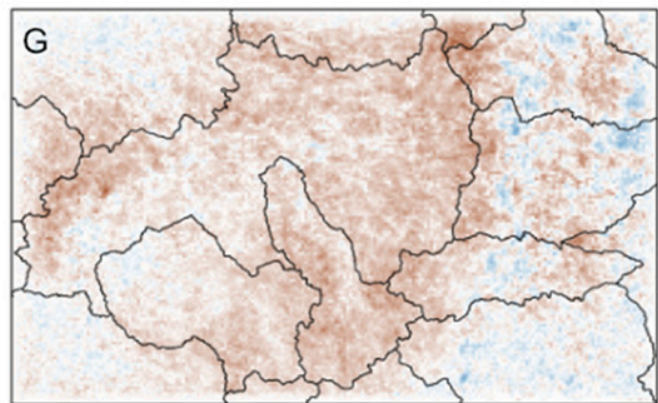

WRF $_{\text {PFIC }}-$ WRF mCAPE difference $\left(\mathrm{J} \mathrm{kg}^{-1}\right)$
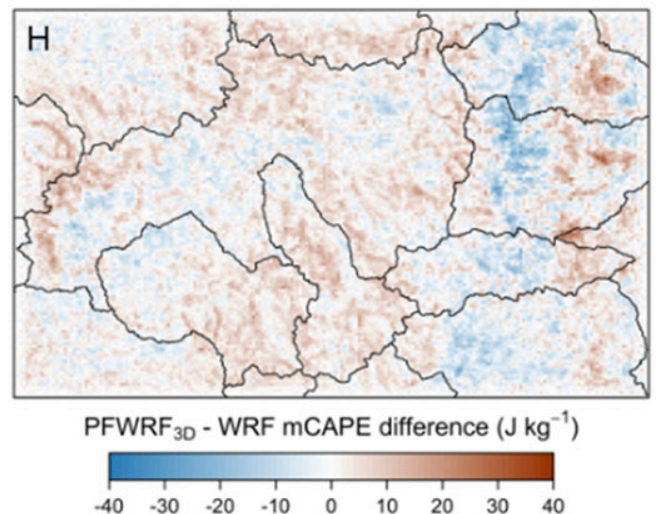

FIG. 15. (a) Cumulative precipitation and (e) mean 1400 LT daily maximum convective potential energy for WRF. Difference from WRF baseline for (b)-(d) cumulative precipitation and (f)-(h) maximum convective available potential energy for $\mathrm{PFWFF}_{\mathrm{FD}}, \mathrm{WRF}_{\mathrm{PFIC}}$, and $\mathrm{PFWRF}_{3 \mathrm{D}}$, respectively. 
WRF mean 1400 LT maximum convective available potential energy (CAPE) averaged over the summer simulation. CAPE is the buoyancy between the level of free convection and the level of neutral buoyancy (Kirshbaum et al. 2018) and is a measure for the potential for lifting, convection, storm generation and severe weather. Note that for this domain, while the mean afternoon CAPE typically ranges between 100 and $300 \mathrm{~J} \mathrm{~kg}^{-1}$, large synoptic storms in the late summer can cause CAPE to reach over $1500 \mathrm{~J} \mathrm{~kg}^{-2}$ in some locations; we have found that perturbations to these large convective events from the lower boundary to be highly noisy and disorganized. However, low levels of CAPE persist from April through June, with domain-averaged afternoon CAPE approximately $55 \mathrm{~J} \mathrm{~kg}^{-2}$. Only 6 individual days in May experience a domain maximum CAPE of over $400 \mathrm{~J} \mathrm{~kg}^{-2}$. The largest CAPE values on average occur at $1400 \mathrm{LT}$.

Differences between mean WRF 1400 LT CAPE and the three lower boundary tests are shown in Figs. 15f-h. Kirshbaum et al. (2018) suggest that in order for moist convection initiation to occur for cloud generation along mountain ridges, convective energy must be sufficient enough to overcome adverse forces, such as ABL entrainment, which can reduce cloud buoyancy through evaporative cooling. By reducing available moisture at the surface, the PFWRF ${ }_{\mathrm{FD}}$ simulation reduces CAPE compared to WRF. PFWRF $F_{F D}$ also may have resulted in perturbed entrainment of dry air from the troposphere and exhibited an overall drier convective boundary layer. $\mathrm{WRF}_{\mathrm{PFIC}}$ shows the opposite effect: an overall wetter initial soil moisture condition increases 1400 LT CAPE by up to $38 \mathrm{~J} \mathrm{~kg}^{-2}$ across the domain relative to $\mathrm{WRF}$, and the boundary layer is generally wetter.

PFWRF $_{3 \mathrm{D}}$ exhibits more variability in its influence on CAPE from the control WRF simulation: PFWRF $_{3 D}$ CAPE is higher on ridges along the Colorado Headwaters boundary but lower along the east slope of the Front Range. To highlight where these changes occur, Fig. 16 zooms in on a ridge and valley on the northern of the Blue Watershed, showing the difference between the WRF control simulation and PFWRF $F_{\mathrm{FD}}, \mathrm{WRF}_{\mathrm{PFIC}}$, and PFWRF $_{3 \mathrm{D}}$. Shown are evaporative fraction, CAPE and wind speed in the direction of the prevailing winds. Notice that $\mathrm{PFWRF}_{3 \mathrm{D}}$ experiences higher latent heating and correspondingly higher CAPE (up to $40 \%$ higher) in the Blue Watershed valley (Fig. 16c), while CAPE along the southwest ridge decreases by $5 \%-15 \%$ (Fig. 16f). This effect is noisy, indicating that latent heating is not the only driver impacting convective energy. To some extent, $\mathrm{WRF}_{\mathrm{PFIC}}$ shows a similar pattern, but the effect is much less clear.

In general, higher CAPE creates more favorable conditions for ascending cloudy thermals and potential orographic precipitation, suggesting that $\mathrm{WRF}_{\mathrm{PFIC}}$, and ridges in $\mathrm{PFWRF}_{3 \mathrm{D}}$ may have slightly higher potential for precipitation; however, thermally driven flows can also cause cloudiness over ridges by ABL convergence from prevailing winds and upslope flows (Kirshbaum et al. 2018). Figures $16 \mathrm{~g}-\mathrm{i}$ shows the difference between WRF 10-m wind speed (in the direction of the prevailing westerly winds) and that of the three other hydrologic schemes. In $\mathrm{PFWRF}_{\mathrm{FD}}$, lateral winds speed is higher, with the leeward side of ridges being less sensitive to perturbations from the free-draining condition. $\mathrm{WRF}_{\mathrm{PFIC}}$ shows reduced wind speed in valleys, possibly an effect of increased vertical lifting of moist air through latent heating. In Fig. 16, PFWRF $_{3 \mathrm{D}}$ exhibits slower mean westerly winds within the valleys and especially on the northeast slopes, which could indicate that daytime upslope flows are stronger or more frequent. Given that westerly winds on the windward slope in Fig. 16 are higher in the PFWRF $3 \mathrm{D}$ case, it suggests that incorporating lateral groundwater flow increases the strength of prevailing and opposing upslope winds converging over ridges in this location, which could increase ABL convergence over ridges. These results, as well as those in Figs. 13 and 14, corroborate the idea that surface moisture and temperature anomalies, which are highly dependent upon soil moisture redistribution schemes, can affect the strength of regional anabatic flows. Other studies have shown sensitivity of mesoscale mountain-breeze circulations to subsurface moisture: in $2 \mathrm{D}$, idealized models, Ookouchi et al. (1984) showed that soil moisture spatial heterogeneity could affect mountain-breeze strength, and Bossert and Cotton (1994a,b) found similar sensitivity of Front Range upslope flows to soil moisture-induced temperature anomalies. These effects can have complicated and contrasting impacts to regional precipitation; we recommend that the coupled hydrology-atmosphere community continue to explore these possibilities with controlled, idealized experiments and realistic mesoscale simulations.

\section{Conclusions}

This study presented results from summertime WRF simulations in the Rocky Mountain headwaters region in 2008. A suite of four models were run with various adjustments to the Noah LSM representation of soil moisture redistribution and terrestrial hydrology: a default WRF control case; a deep, free-draining model with an adjusted infiltration scheme and soil hydraulic parameters $\left(\right.$ PFWRF $\left._{\mathrm{FD}}\right)$; a default WRF Model initialized with a hydrologic model spinup for soil moisture $\left(\mathrm{WRF}_{\mathrm{PFIC}}\right)$; and a fully coupled, three-dimensional representation of integrated subsurface-surface hydrology $\left(\mathrm{PFWRF}_{3 \mathrm{D}}\right)$. 


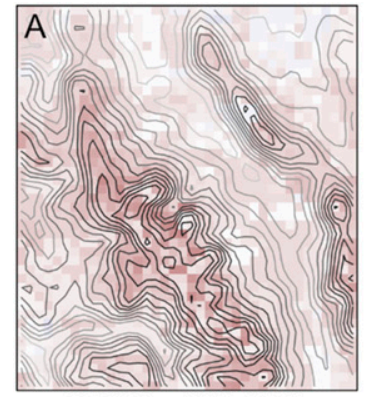

PFWRF $_{F D}-$ WRF $\triangle E F(-)$
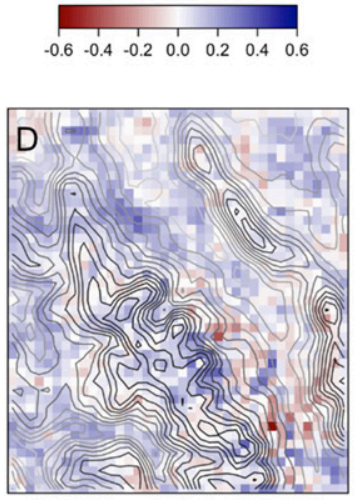

PFWRF $_{F D}$ - WRF $\triangle \mathrm{MCAPE}(\%)$
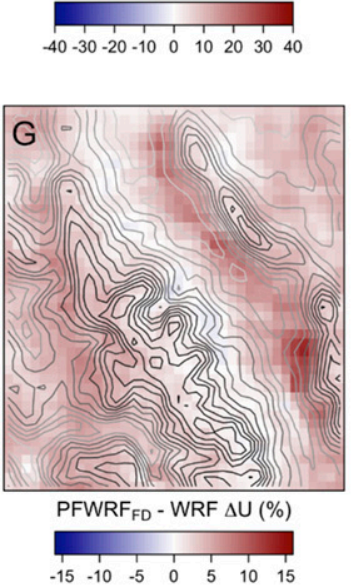

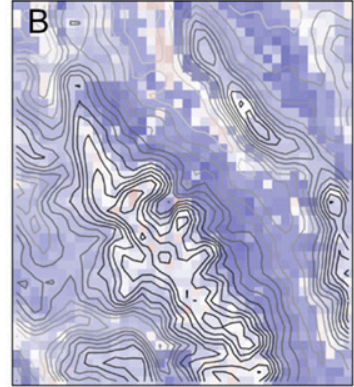

WRF $_{\text {PFIC }}-$ WRF $\triangle E F(-)$
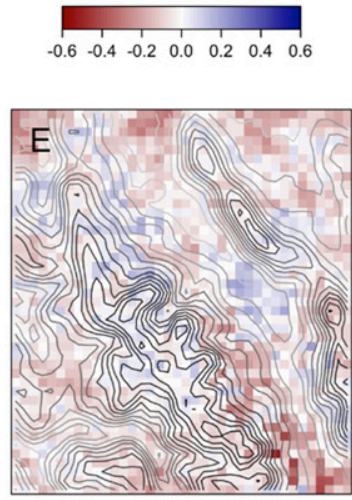

$W_{R F}$ PFIC - WRF $\triangle \mathrm{mCAPE}(\%)$

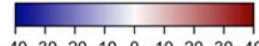

$-40-30-20-10 \quad 0 \quad 10 \quad 20 \quad 30 \quad 40$

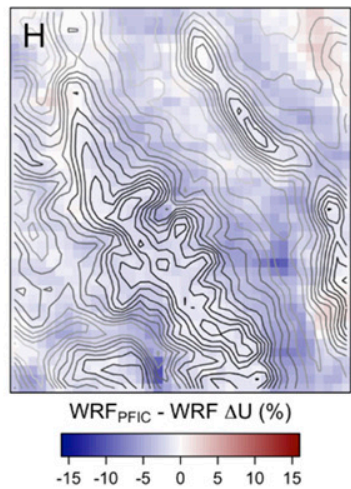

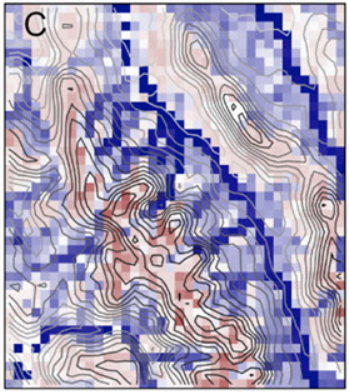

$\mathrm{PFWRF}_{3 \mathrm{D}}-\mathrm{WRF} \triangle \mathrm{EF}(-)$
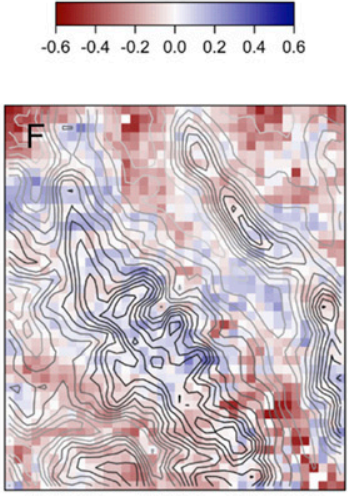

PFWRF $_{3 D}-$ WRF $\triangle \mathrm{MCAPE}(\%)$

$-40-30-20-10 \quad 0-10-20-30-40$

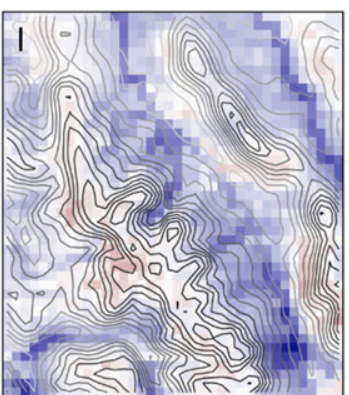

$\mathrm{PFWRF}_{3 \mathrm{D}}-\mathrm{WRF} \Delta \mathrm{U}(\%)$

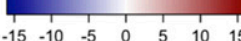

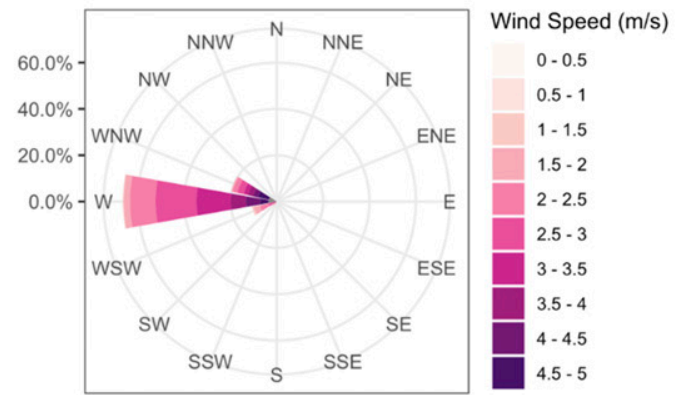

Elevation (m)

2000

$-2300$

$-2600$

- 2900

$-\quad 3200$

FIG. 16. Difference between the control WRF simulation and (left) PFWRF FD, (center)

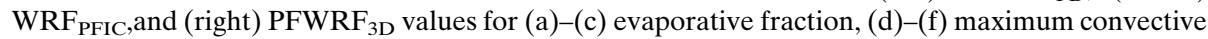
available potential energy, and $(\mathrm{h})-(\mathrm{j})$ prevailing wind speed. Topographic contours between 2000 and $3500 \mathrm{~m}$ are overlain and a wind rose for the prevailing flows is shown. 
Results showed considerable differences in soil moisture and evaporative fraction, planetary boundary layer characteristics and land-atmosphere coupling. Lateral subsurface flow routes moisture from hilltops to valleys, resulting in comparatively cooler, moisture, and lower ABL in regions of topographic convergence. For a region of predominantly orographic precipitation, in which topographic highs receive the greatest amount of recharge, the ability for water in the soil column to flow in response to complex terrain influences local circulation patterns and meteorological forecasts. Unlike many traditional LSMs, $\mathrm{PFWRF}_{3 \mathrm{D}}$ transports the elevation-dependent precipitation to topographic lows. Lateral groundwater flow incorporation in the atmospheric model was shown to affect low levels of convection, particularly by increasing the mean afternoon convective available potential energy in river valleys, and it may increase the strength of anabatic mountain-valley circulation.

The results are of major consequence to studies of groundwater-atmosphere coupling and feedbacks; in particular, there is much work to be done in examining the impact of LSM hydrologic physics on convection and precipitation. Vivoni et al. (2009) showed that antecedent moisture conditions significantly influence precipitation predicted by WRF during the North American monsoon in the southwest United States. They found that simulated cumulative rainfall was sensitive to a multiplier applied to the initial soil moisture fields, with higher antecedent moisture portending higher evapotranspiration and precipitation rates. The results of this study also implicate the use of hydrologic models to establish initial soil moisture conditions, for 1) mechanistic representation of local moisture redistribution, to supplement downscaled conditions from coarse-resolution atmospheric products (Peng et al. 2017), 2) initializing moisture at an equilibrium state in order to minimize initial condition bias, and 3) limiting the higher computational demands of a fully coupled, hydrology-atmosphere modeling platform.

Our comparison of meteorological simulations that employ different lower boundary conditions highlights a fact already well established in the literature: that both soil moisture and groundwater provide important controls on planetary boundary layer development. Given that incorporation of a lateral flow component not only changes the magnitude and spatial heterogeneity of both turbulent fluxes and ABL height, but also mechanistically adjusts the physical coupling between land and atmosphere, the results here warrant further investigation of LSM hydrologic assumptions.

Acknowledgments. The authors gratefully acknowledge funding, in part from the National Science Foundation Water Sustainability and Climate (WSC) program NSF
Grant 1204787, and additionally from the U.S. Department of Energy, Interoperable Design of Extreme-scale Application Software (IDEAS) Project under Award Number DE-AC02-05CH11231. High-performance computing for WRF simulations were provided by the National Center for Atmospheric Research Computational and Information Systems Laboratory.

Data availability statement: The coupled WRF-ParFlow model is openly available at https://github.com/parflow. Raw model data were generated using computational resources provided by the National Center for Atmospheric Research Computational and Information Systems Laboratory. Model outputs are available from the authors upon request.

\section{REFERENCES}

Ajami, H., M. F. McCabe, J. P. Evans, and S. Stisen, 2014: Assessing the impact of model spin-up on surface watergroundwater interactions using an integrated hydrologic model. Water Resour. Res., 50, 2636-2656, https://doi.org/ 10.1002/2013WR014258.

Anyah, R. O., C. P. Weaver, G. Miguez-Macho, Y. Fan, and A. Robock, 2008: Incorporating water table dynamics in climate modeling: 3. Simulated groundwater influence on coupled land-atmosphere variability. J. Geophys. Res., 113, D07103, https://doi.org/10.1029/2007JD009087.

Bachmair, S., and M. Weiler, 2011: New dimensions of hillslope hydrology. Forest Hydrology and Biogeochemistry, D. Levia, D. Carlyle-Moses, and T. Tanaka, Eds., Springer, 455-481.

Baldauf, M., A. Seifert, J. Förstner, D. Majewski, M. Raschendorfer, and T. Reinhardt, 2011: Operational convective-scale numerical weather prediction with the COSMO model: Description and sensitivities. Mon. Wea. Rev., 139, 3887-3905, https://doi.org/ 10.1175/MWR-D-10-05013.1.

Banta, R. M., 1984: Daytime boundary-layer evolution over mountainous terrain. Part I: Observations of the dry circulations. Mon. Wea. Rev., 112, 340-356, https://doi.org/10.1175/ 1520-0493(1984)112<0340:DBLEOM > 2.0.CO;2.

Best, M. J., and Coauthors, 2015: The plumbing of land surface models: Benchmarking model performance. J. Hydrometeor., 16, 1425-1442, https://doi.org/10.1175/JHM-D-14-0158.1.

Betts, R. A., P. M. Cox, S. E. Lee, and F. I. Woodward, 1997: Contrasting physiological and structural vegetation feedbacks in climate change simulations. Nature, 387, 796-799, https:// doi.org/10.1038/42924.

Bossert, J. E., and W. R. Cotton, 1994a: Regional-scale flows in mountainous terrain. Part I: A numerical and observational comparisons. Mon. Wea. Rev., 122, 1449-1471, https://doi.org/ 10.1175/1520-0493(1994)122<1449:RSFIMT>2.0.CO;2.

_, and _ 1994b: Regional-scale flows in mountainous terrain. Part II: Simplified numerical experiments. Mon. Wea. Rev., 122, 1472-1489, https://doi.org/10.1175/1520-0493(1994) $122<1472$ :RSFIMT $>2.0 . \mathrm{CO} ; 2$.

Braun, F. J., and G. Schädler, 2005: Comparison of soil hydraulic parameterizations for mesoscale meteorological models. J. Appl. Meteor., 44, 1116-1132, https://doi.org/ 10.1175/JAM2259.1.

Brubaker, K. L., and D. Entekhabi, 1996: Analysis of feedback mechanisms in land-atmosphere interaction. Water Resour. Res., 32, 1343-1357, https://doi.org/10.1029/96WR00005. 
Burns, S. P., G. D. Maclean, P. D. Blanken, S. P. Oncley, S. R. Semmer, and R. K. Monson, 2016: The Niwot Ridge subalpine forest US-NR1 AmeriFlux site - Part I: Data acquisition and site record-keeping. Geosci. Instrum. Methods Data Syst., 5, 451-471, https://doi.org/10.5194/gi-5-451-2016.

Celia, M. A., E. T. Bouloutas, and R. L. Zarba, 1990: A general mass-conservative numerical solution for the unsaturated flow equation. Water Resour. Res., 26, 1483-1496, https://doi.org/ 10.1029/WR026i007p01483.

Chen, F., and J. Dudhia, 2001: Coupling an advanced land surfacehydrology model with the Penn State-NCAR MM5 modeling system. Part I: Model implementation and sensitivity. Mon. Wea. Rev., 129, 569-585, https://doi.org/10.1175/1520-0493(2001) $129<0569:$ CAALSH $>2.0 . \mathrm{CO} ; 2$.

_ , and Coauthors, 2014: Modeling seasonal snowpack evolution in the complex terrain and forested Colorado Headwaters region: A model intercomparison study. J. Geophys. Res. Atmos., 119, 13 795-13 819, https://doi.org/10.1002/2014JD022167.

Christensen, N. S., A. W. Wood, N. Voisin, D. P. Lettenmaier, and R. N. Palmer, 2004: The effects of climate change on the hydrology and water resources of the Colorado River Basin. Climatic Change, 62, 337-363, https://doi.org/10.1023/B: CLIM.0000013684.13621.1f.

Clapp, R. B., and G. M. Hornberger, 1978: Empirical equations for some soil hydraulic properties. Water Resour. Res., 14, 601604, https://doi.org/10.1029/WR014i004p00601.

Cosby, B. J., G. M. Hornberger, R. B. Clapp, and T. R. Ginn, 1984: A statistical exploration of the relationships of soil moisture characteristics to the physical properties of soils. Water Resour. Res., 20, 682-690, https://doi.org/10.1029/WR020i006p00682.

Cosgrove, B. A., 2003: Real-time and retrospective forcing in the North American Land Data Assimilation System (NLDAS) project. J. Geophys. Res., 108, 8842, https://doi.org/10.1029/ 2002JD003118.

Defant, F., 1951: Local winds. Compendium of Meteorology, T. M. Malone, Ed., Amer. Meteor. Soc., 655-672.

Dickinson, R. E., M. Shaikh, R. Bryant, and L. Graumlich, 1998: Interactive canopies for a climate model. J. Climate, 11, 2823-2836, https://doi.org/10.1175/1520-0442(1998)011<2823: ICFACM $>2.0 . \mathrm{CO} ; 2$.

Dudhia, J., 1989: Numerical study of convection observed during the winter monsoon experiment using a mesoscale two-dimensional model. J. Atmos. Sci., 46, 3077-3107, https://doi.org/10.1175/ 1520-0469(1989)046<3077:NSOCOD >2.0.CO;2.

Entekhabi, D., I. Rodriguez-Iturbe, and F. Castelli, 1996: Mutual interaction of soil moisture state and atmospheric processes. J. Hydrol., 184, 3-17, https://doi.org/10.1016/0022-1694(95) 02965-6.

Fan, Y., G. Miguez-Macho, C. P. Weaver, R. Walko, and A. Robock, 2007: Incorporating water table dynamics in climate modeling 1 : Water table observations and equilibrium water table simulations. J. Geophys. Res., 112, D10125, https://doi.org/10.1029/ 2006JD008111.

Ficklin, D. L., I. T. Stewart, and E. P. Maurer, 2013: Climate change impacts on streamflow and subbasin-scale hydrology in the upper Colorado River Basin. PLoS One, 8, e71297, https:// doi.org/10.1371/journal.pone.0071297.

Findell, K. L., and E. A. B. Eltahir, 2003: Atmospheric controls on soil moisture-boundary layer interactions. Part I: Framework development. J. Hydrometeor., 4, 552-569, https://doi.org/ 10.1175/1525-7541(2003)004<0552:ACOSML>2.0.CO;2.

Forrester, M. M., R. M. Maxwell, L. Bearup, and D. Gochis, 2018: Forest disturbance feedbacks from bedrock to atmosphere using coupled hydro-meteorological simulations over the Rocky mountain headwaters. J. Geophys. Res. Atmos., 123, 9026-9046, https://doi.org/10.1029/2018JD028380.

Gilding, B. H., 1991: Qualitative mathematical analysis of the Richards equation. Transp. Porous Media, 6, 651-666, https:// doi.org/10.1007/978-94-017-2199-8_11.

Gleeson, T., L. Smith, N. Moosdorf, J. Hartmann, H. H. Dürr, A. H. Manning, L. P. H. van Beek, and A. M. Jellinek, 2011a: Mapping permeability over the surface of the Earth. Geophys. Res. Lett., 38, L02401, https://doi.org/10.1029/2010GL045565.

_ L. Marklund, L. Smith, and A. H. Manning, 2011b: Classifying the water table at regional to continental scales. Geophys. Res. Lett., 38, 05401, https://doi.org/10.1029/2010GL046427.

Gochis, D. J., W. Yu, and D. N. Yates, 2015: The WRF-Hydro model technical description and user's guide, version 3.0. NCAR Tech. Doc., 120 pp., http://www.ral.ucar.edu/projects/wrf_hydro/.

Gulden, L. E., E. Rosero, Z.-L. Yang, M. Rodell, C. S. Jackson, G.-Y. Niu, P. J.-F. Yeh, and J. Famiglietti, 2007: Improving land-surface model hydrology: Is an explicit aquifer model better than a deeper soil profile? Geophys. Res. Lett., 34, L09402, https://doi.org/10.1029/2007GL029804.

Hanks, R. J., and G. L. Ashcroft, Eds., 1980: Applied soil physics. Soil Water and Temperature Applications, Advanced Series in Agricultural Sciences, Vol. 8. Springer, 1-22, https://doi.org/ 10.1007/978-1-4684-0184-4.

Henderson-Sellers, A., Z.-L. Yang, and R. E. Dickinson, 1993: The project for intercomparison of land-surface parameterization schemes. Bull. Amer. Meteor. Soc., 74, 1335-1349, https:// doi.org/10.1175/1520-0477(1993)074<1335:TPFIOL >2.0.CO;2.

Hong, S.-Y., Y. Noh, and J. Dudhia, 2006: A new vertical diffusion package with an explicit treatment of entrainment processes. Mon. Wea. Rev., 134, 2318-2341, https://doi.org/ 10.1175/MWR3199.1.

Jacquemin, B., and J. Noilhan, 1990: Sensitivity study and validation of a land surface parameterization using the HAPEXMOBILHY data set. Bound.-Layer Meteor., 52, 93-134, https://doi.org/10.1007/BF00123180.

Jiang, X., G.-Y. Niu, and Z.-L. Yang, 2009: Impacts of vegetation and groundwater dynamics on warm season precipitation over the central United States. J. Geophys. Res., 114, D06109, https://doi.org/10.1029/2008JD010756.

Jones, J. E., and C. S. Woodward, 2001: Newton-Krylov-multigrid solvers for large-scale, highly heterogeneous, variably saturated flow problems. Adv. Water Resour., 24, 763-774, https:// doi.org/10.1016/S0309-1708(00)00075-0.

Kain, J. S., 2004: The Kain-Fritsch convective parameterization: An update. J. Appl. Meteor., 43, 170-181, https://doi.org/ 10.1175/1520-0450(2004)043<0170:TKCPAU>2.0.CO;2.

Keune, J., F. Gasper, K. Goergen, A. Hense, P. Shrestha, M. Sulis, and S. Kollet, 2016: Studying the influence of groundwater representations on land surface-atmosphere feedbacks during the European heat wave in 2003. J. Geophys. Res. Atmos., 121, 13 301-13 325, https://doi.org/10.1002/2016JD025426.

Kim, Y., and G. Wang, 2007: Impact of initial soil moisture anomalies on subsequent precipitation over North America in the coupled land-atmosphere model CAM3-CLM3. J. Hydrometeor., 8, 513533, https://doi.org/10.1175/JHM611.1.

Kirshbaum, D. J., B. Adler, N. Kalthoff, C. Barthlott, and S. Serafin, 2018: Moist orographic convection: Physical mechanisms and links to surface-exchange processes. Atmosphere, 9, 80, https:// doi.org/10.3390/atmos9030080.

Kollet, S. J., and R. M. Maxwell, 2006: Integrated surfacegroundwater flow modeling: A free-surface overland flow 
boundary condition in a parallel groundwater flow model. Adv. Water Resour., 29, 945-958, https://doi.org/10.1016/ j.advwatres.2005.08.006.

$\longrightarrow$, and - 2008: Capturing the influence of groundwater dynamics on land surface processes using an integrated, distributed watershed model. Water Resour. Res., 44, W02402, https://doi.org/10.1029/2007WR006004.

Koster, R. D., M. J. Suarez, R. W. Higgins, and H. M. van den Dool, 2003: Observational evidence that soil moisture variations affect precipitation. Geophys. Res. Lett., 30, 1241, https:// doi.org/10.1029/2002GL016571.

Lawrence, D. M., and Coauthors, 2011: Parameterization improvements and functional and structural advances in version 4 of the Community Land Model. J. Adv. Model. Earth Syst., 3 , M03001, https://doi.org/10.1029/2011MS00045.

Manabe, S., 1969: Climate and the ocean circulation: 1 . The atmospheric circulation and the hydrology of the earth's surface. Mon. Wea. Rev., 97, 739-774, https://doi.org/10.1175/ 1520-0493(1969)097<0739:CATOC >2.3.CO;2.

Manning, A. H., P. L. Verplanck, J. S. Caine, and A. S. Todd, 2013: Links between climate change, water table depth, and water chemistry in a mineralized mountain watershed. Appl. Geochem., 37, 64-78, https://doi.org/10.1016/j.apgeochem.2013.07.002.

Maxwell, R. M., 2013: A terrain-following grid transform and preconditioner for parallel, large-scale, integrated hydrologic modeling. Adv. Water Resour., 53, 109-117, https://doi.org/ 10.1016/j.advwatres.2012.10.001.

_ dynamics and land-energy feedbacks under climate change. Nat. Geosci., 1, 665-669, https://doi.org/10.1038/ngeo315.

$\longrightarrow$, and $-2008 \mathrm{~b}$ : Quantifying the effects of three-dimensional subsurface heterogeneity on Hortonian runoff processes using a coupled numerical, stochastic approach. Adv. Water Resour., 31, 807-817, https://doi.org/10.1016/j.advwatres.2008.01.020.

— flow and transpiration partitioning. Science, 353, 377-380, https://doi.org/10.1126/science.aaf7891.

_ , F. K. Chow, and S. J. Kollet, 2007: The groundwater-landsurface-atmosphere connection: Soil moisture effects on the atmospheric boundary layer in fully coupled simulations. Adv. Water Resour., 30, 2447-2466, https://doi.org/10.1016/ j.advwatres.2007.05.018.

- J. K. Lundquist, J. D. Mirocha, S. G. Smith, C. S. Woodward, and A. F. B. Tompson, 2011: Development of a coupled groundwater-atmosphere model. Mon. Wea. Rev., 139, 96116, https://doi.org/10.1175/2010MWR3392.1.

— L. E. Condon, and S. J. Kollet, 2015: A high-resolution simulation of groundwater and surface water over most of the continental US with the integrated hydrologic model ParFlow v3. Geosci. Model Dev., 8, 923-937, https://doi.org/10.5194/ gmd-8-923-2015.

_ , and Coauthors, 2016: ParFlow user's manual. Integrated Groundwater Modeling Center Report GWMI 2016-01, 167 pp., https://inside.mines.edu/ rmaxwell/parflow.manual.2-15-16.pdf.

Miguez-Macho, G., Y. Fan, C. P. Weaver, R. Walko, and A. Robock, 2007: Incorporating water table dynamics in climate modeling: 2. Formulation, validation, and soil moisture simulation. J. Geophys. Res., 112, D13108, https://doi.org/10.1029/2006JD008112.

Mlawer, E. J., S. J. Taubman, P. D. Brown, M. J. Iacono, and S. A. Clough, 1997: Radiative transfer for inhomogeneous atmospheres: RRTM, a validated correlated-K model for the longwave. J. Geophys. Res., 102, 16 663-16 682, https://doi.org/ 10.1029/97JD00237.
Monson, R. K., A. A. Turnipseed, J. P. Sparks, P. C. Harley, L. E. Scott-Denton, K. Sparks, and T. E. Huxman, 2002: Carbon sequestration in a high-elevation, subalpine forest. Global Change Biol., 8, 459-478, https://doi.org/10.1046/ j.1365-2486.2002.00480.x.

National Operational Hydrologic Remote Sensing Center, 2004: Snow Data Assimilation System (SNODAS) data products at NSIDC, version 1. National Snow and Ice Data Center, accessed 8 September 2019, http://doi.org/10.7265/N5TB14TC.

NOAA/NCEP, 2000: NCEP FNL Operational Model Global Tropospheric Analyses, continuing from July 1999 (updated daily). National Center for Atmospheric Research Computational and Information Systems Laboratory Research Data Archive, accessed 1 September 2019, https://doi.org/10.5065/ D6M043C6.

Niu, G.-Y., Z.-L. Yang, R. E. Dickinson, L. E. Gulden, and H. Su, 2007: Development of a simple groundwater model for use in climate models and evaluation with Gravity Recovery and Climate Experiment data. J. Geophys. Res., 112, D07103, https://doi.org/10.1029/2006JD007522.

Oleson, K. W., and Coauthors, 2008: Improvements to the Community Land Model and their impact on the hydrological cycle. J. Geophys. Res., 113, G01021, https://doi.org/10.1029/ 2007JG000563.

Ookouchi, Y., M. Segal, R. C. Kessler, and R. A. Pielke, 1984: Evaluation of soil moisture effects on the generation and modification of mesoscale circulations. Mon. Wea. Rev., 112, 2281-2292, https://doi.org/10.1175/1520-0493(1984)112<2281: EOSMEO $>2.0 . \mathrm{CO} ; 2$.

Peng, J., A. Loew, O. Merlin, and N. E. C. Verhoest, 2017: A review of spatial downscaling of satellite remotely sensed soil moisture. Rev. Geophys., 55, 341-366, https://doi.org/ 10.1002/2016RG000543.

Penman, H. L., 1948: Natural evaporation from open water, hare soil and grass. Proc. Roy. Soc. London, 193A, 120-145, https:// doi.org/10.1098/RSPA.1948.0037.

Pielke, R. A., 2001: Influence of the spatial distribution of vegetation and soils on the prediction of cumulus Convective rainfall. Rev. Geophys., 39, 151-177, https://doi.org/10.1029/ 1999RG000072.

Rahman, M., M. Sulis, and S. J. Kollet, 2015: The subsurface-land surface-atmosphere connection under convective conditions. Adv. Water Resour., 83, 240-249, https://doi.org/10.1016/ j.advwatres.2015.06.003.

Rampanelli, G., D. Zardi, and R. Rotunno, 2004: Mechanicsms of up-valley winds. J. Atmos. Sci., 61, 3097-3111, https://doi.org/ 10.1175/JAS-3354.1.

Richards, L. A., 1931: Capillary conduction of liquids through porous mediums. Physics, 1, 318-333, https://doi.org/10.1063/ 1.1745010.

Riveros-Iregui, D. A., B. L. McGlynn, R. E. Emanuel, and H. E. Epstein, 2012: Complex terrain leads to bidirectional responses of soil respiration in inter-annual water availability. Global Change Biol., 18, 749-756, https://doi.org/10.1111/ j.1365-2486.2011.02556.x.

Rodriguez-Iturbe, I., 2000: Ecohydrology: A hydrologic perspective of climate-soil-vegetation dynamies. Water Resour. Res., 36, 3-9, https://doi.org/10.1029/1999WR900210.

Santanello, J. A., Jr., C. D. Peters-Lidard, S. V. Kumar, C. Alonge, and W.-K. Tao, 2009: A modeling and observational framework for diagnosing local land-atmosphere coupling on diurnal time scales. J. Hydrometeor., 10, 577-599, https://doi.org/ 10.1175/2009JHM1066.1. 
and - 2011: Diagnosing the sensitivity of local landatmosphere coupling via the soil moisture-boundary layer interaction. J. Hydrometeor., 12, 766-786, https://doi.org/ 10.1175/JHM-D-10-05014.1.

_ J. Joundy, and P. A. Dirmeyer, 2015: Quantifying the landatmosphere coupling behavior in modern reanalysis products over the U.S. Southern Great Plains. J. Climate, 28, 5813-5829, https://doi.org/10.1175/JCLI-D-14-00680.1.

Schaake, J. C., V. I. Koren, Q.-Y. Duan, K. Mitchell, and F. Chen, 1996: Simple water balance model for estimating runoff at different spatial and temporal scales. J. Geophys. Res., 101, 7461-7475, https://doi.org/10.1029/95JD02892.

Schaap, M. G., and F. J. Leij, 1998: Database-related accuracy and uncertainty of pedotransfer functions. Soil Sci., 163, 765-779, https://doi.org/10.1097/00010694-199810000-00001.

Sellers, P. J., Y. Mintz, Y. C. Sud, and A. Dalcher, 1986: A Simple Biosphere Model (SIB) for use within general circulation models. J. Atmos. Sci., 43, 505-531, https://doi.org/10.1175/ 1520-0469(1986)043<0505:ASBMFU>2.0.CO;2.

Senatore, A., G. Mendicino, D. J. Gochis, W. Yu, D. N. Yates, and H. Kunstmann, 2015: Fully coupled atmosphere-hydrology simulations for the central Mediterranean: Impact of enhanced hydrological parameterization for short and long time scales. J. Adv. Model. Earth Syst., 7, 1693-1715, https://doi.org/ 10.1002/2015MS000510.

Seuffert, G., P. Gross, and C. Simmer, 2002: The Influence of hydrologic modeling on the predicted local weather: Two-way coupling of a mesoscale weather prediction model and a land surface hydrologic model. J. Hydrometeor., 3, 505-523, https://doi.org/10.1175/1525-7541(2002)003<0505:TIOHMO> 2.0.CO;2.

Shrestha, P., M. Sulis, M. Masbou, S. Kollet, and C. Simmer, 2014: A scale-consistent terrestrial systems modeling platform based on COSMO, CLM, and ParFlow. Mon. Wea. Rev., 142, 3466-3483, https://doi.org/10.1175/MWR-D-14-00029.1.

Skamarock, W. C., and Coauthors, 2008: A description of the Advanced Research WRF version 3. NCAR Tech. Note NCAR/TN-475+STR, 113 pp., http://doi.org/10.5065/D68S4MVH.

Soil Survey Staff, 2019: Soil Survey Geographic (SSURGO) database for Colorado. USDA Natural Resources Conservation Service, accessed 8 September 2019, https://www.nrcs.usda.gov/wps/ portal/nrcs/detail/soils/survey/?cid=nrcs142p2_053627.

Soulis, E. D., K. R. Snelgrove, N. Kouwen, F. Seglenieks, and D. L. Verseghy, 2000: Towards closing the vertical water balance in Canadian atmospheric models: Coupling of the land surface scheme class with the distributed hydrological model watflood. Atmos.-Ocean, 38, 251-269, https://doi.org/ 10.1080/07055900.2000.9649648.
Sulis, M., J. Keune, P. Shrestha, C. Simmer, and S. J. Kollet, 2018: Quantifying the impact of subsurface-land surface physical processes on the predictive skill of subseasonal mesoscale atmospheric simulations. J. Geophys. Res. Atmos., 123, 91319151, https://doi.org/10.1029/2017JD028187.

Thompson, G., P. R. Field, R. M. Rasmussen, and W. D. Hall, 2008: Explicit forecasts of winter precipitation using an improved bulk microphysics scheme. Part II: Implementation of a new snow parameterization. Mon. Wea. Rev., 136, 5095-5115, https://doi.org/10.1175/2008MWR2387.1.

Turnipseed, A. A., D. E. Anderson, S. Burns, P. D. Blanken, and R. K. Monson, 2004: Airflows and turbulent flux measurements in mountainous terrain. Agric. For. Meteor., 125, 187205, https://doi.org/10.1016/j.agrformet.2004.04.007.

van Genuchten, M. T., 1980: A closed-form equation for predicting the hydraulic conductivity of unsaturated soils. Soil Sci. Soc. Amer. J., 44, 892-898, https://doi.org/10.2136/ sssaj1980.03615995004400050002x.

Vivoni, E. R., K. Tai, and D. J. Gochis, 2009: Effects of initial soil moisture on rainfall generation and subsequent hydrologic response during the North American monsoon. J. Hydrometeor., 10, 644-664, https://doi.org/10.1175/2008JHM1069.1.

Webb, E. K., G. I. Pearman, and R. Leuning, 1980: Correction of flux measurements for density effects due to heat and water vapor transfer. Quart. J. Roy. Meteor. Soc., 106, 85-100, https://doi.org/10.1002/QJ.49710644707.

Whiteman, C. D., X. Bian, and S. Zhong, 1999: Wintertime evolution of the temperature inversion in the Colorado Plateau Basin. J. Appl. Meteor., 38, 1103-1117, https://doi.org/10.1175/ 1520-0450(1999)038<1103:WEOTTI >2.0.CO;2.

Williams, J. L., and R. M. Maxwell, 2011: Propagating subsurface uncertainty to the atmosphere using fully coupled stochastic simulations. J. Hydrometeor., 12, 690-701, https://doi.org/ 10.1175/2011JHM1363.1.

Xue, M., K. K. Droegemeier, and V. Wong, 2000: The Advanced Regional Prediction System (ARPS) - A multi-scale nonhydrostatic atmospheric simulation and prediction model. Part I: Model dynamics and verification. Meteor. Atmos. Phys., 75, 161-193, https://doi.org/10.1007/s007030070003.

Yeh, P. J.-F., and E. A. B. Eltahir, 2005: Representation of water table dynamics in a land surface scheme. Part I: Model development. J. Climate, 18, 1861-1880, https://doi.org/10.1175/ JCLI3330.1.

Yucel, I., A. Onen, K. K. Yilmaz, and D. J. Gochis, 2015: Calibration and evaluation of a flood forecasting system: Utility of numerical weather prediction model, data assimilation and satellite-based rainfall. J. Hydrol., 523, 49-66, https://doi.org/10.1016/j.jhydrol.2015.01.042. 